\section{A) Check for updates}

Cite this: Green Chem., 2020, 22, 3693

Received 26th March 2020, Accepted 19th May 2020

DOI: $10.1039 /$ d0gc01074j

rsc.li/greenchem

\title{
Advances in the green chemistry of coordination polymer materials
}

\begin{abstract}
Emile R. Engel (ID) ${ }^{a, b}$ and Janet L. Scott (D) ${ }^{a}$
Coordination polymers, including metal-organic frameworks, are a diverse class of materials with myriad properties and potential applications. However, a number of drawbacks have hindered the scaling up of such materials towards commercial applications. These include health and safety risks, environmental hazards, poor cost efficiency and sustainability shortfalls. In contrast to the systematic progress of organic green chemistry, which has contributed to improvements in the sustainability of chemical processing, the development of green chemistry in the context of coordination polymers has been fragmented and sporadic. This review describes advances in the use of green components: benign sustainable ligands and non-hazardous earth abundant metals. Additionally, solvent considerations, synthesis strategies for improved sustainability and the performance of coordination polymers relative to alternative competing materials are discussed.
\end{abstract}

\section{Introduction}

Coordination polymers (CPs) are metal-ligand coordination compounds that form one-dimensional (1D) extended chains, two-dimensional (2D) sheets or three-dimensional (3D) frameworks. There are two recognised sub-classes: "coordination

${ }^{a}$ Department of Chemistry, University of Bath, Claverton Down, Bath, BA2 7AY, UK. E-mail:ee380@bath.ac.uk

${ }^{b}$ Department of Fibre and Polymer Technology, KTH Royal Institute of Technology, SE-100 44 Stockholm, Sweden networks", which are 2D, 3D or crosslinked 1D CPs, and "metal-organic frameworks" (MOFs) (also referred to as "porous coordination polymers"), which are coordination networks that contain potential voids. ${ }^{1}$ Metallopolymers are a distinct class of organic polymers incorporating metal ions into the backbone or side chains. "Inorganic-organic hybrid materials" is a related term, which may be appropriate when referring to CPs that resemble extended inorganic compounds; ${ }^{3}$ however, in accordance with the approach of Biradha et al. ${ }^{4}$ we have disregarded this term to avoid unnecessary confusion and use a simplified taxonomy as illustrated in Fig. 1.

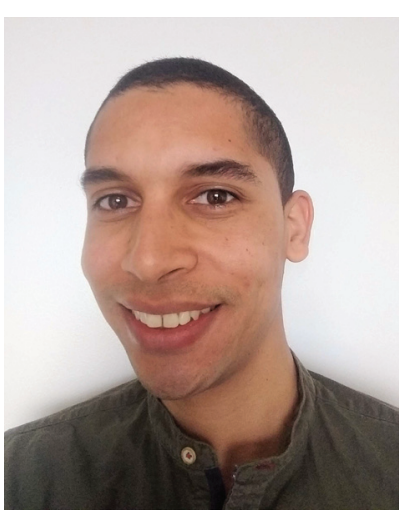

Emile R. Engel
Emile R. Engel completed his PhD in Chemistry at Stellenbosch University, South Africa. He is Visiting Researcher and former Commonwealth Rutherford Fellow in the Department of Chemistry at the University of Bath, UK and Postdoctoral Researcher in the Department of Fibre and Polymer Technology at KTH Royal Institute of Technology, Sweden. His research is directed towards sustainable and functional materials. Specific topics of interest include coordination polymers, host-guest chemistry, molecular crystals and cellulosebased materials.

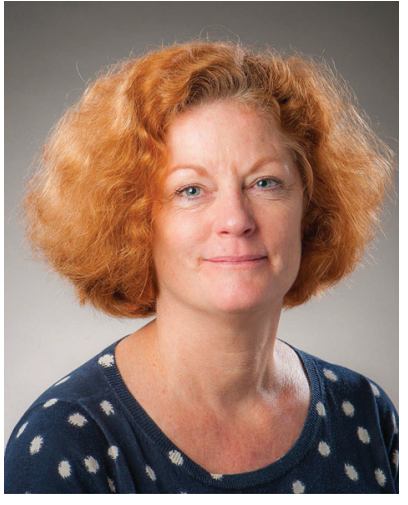

Janet L. Scott
Janet L. Scott is Professor of Sustainable Chemistry in the Department of Chemistry and Training Director of the Centre for Doctoral Training in Sustainable Chemical Technologies at the University of Bath, UK. She has a background in both industry and academia in South Africa, Australia and the UK and her interdisciplinary research is currently focused on renewable, bio-based materials for applications ranging from tissue scaffolds, through nanoparticulate rheology modifiers, to composites and plastic substitutes. 


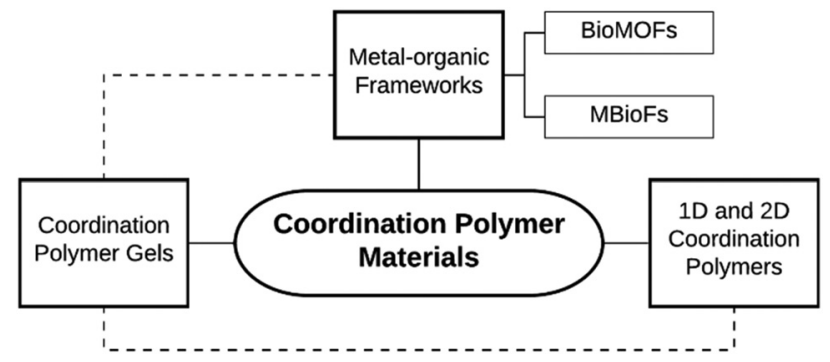

Fig. 1 Relevant classes of CP materials.

Metal biomolecule frameworks (MBioFs) has been proposed as a sub-class of MOFs, where the MOF incorporates "at least one biomolecule" as organic linker and where "biomolecule" refers to naturally-occurring molecules found in living organisms, such as amino acids, nucleobases or sugars. ${ }^{5}$ To be clear, under strict application of this definition, a MBioF may incorporate any metal, including hazardous metal ions, and additional ligands that are not biomolecules. A similar term, BioMOFs, is defined as "metal-organic frameworks for biological and medical applications". ${ }^{6,7}$ Here the focus is on biocompatibility such that these can be used for applications involving living organisms, including humans. Concern for biological safety does not explicitly include all aspects relating to the principles of green chemistry, such as the minimisation of waste or the elimination of hazardous solvents used during synthesis. Nevertheless, CPs that qualify as BioMOFs tend to comprise environmentally benign components, such as MIL-88A, which is constructed from Fe(III) and fumaric acid. ${ }^{8}$ The prefix "MIL" is used for a variety of porous 3D CPs discovered by researchers at Materials Institute Lavoisier.9 "Biobased MOFs" is an emerging category that has not yet been explicitly defined.

Within the field of CP materials, MOFs have received the bulk of research attention in recent years. Fig. 2a shows the number of publications in a given year containing the term "coordination polymer" and those containing "metal-organic framework" in the title, abstract or keywords. The term "metal-organic framework" surpassed "coordination polymer" in 2014 and is now clearly dominant.

In addition to (usually) crystalline and structurally welldefined solid MOFs and CPs, CP gels are an important class of metal-organic materials. A CP may form a network of interacting particles or crystallites within a solvent medium, immobilising the solvent to form a gel. ${ }^{10-12}$ The solvent usually makes up over $95 \mathrm{wt} \%$ of the gel and CP gels may be classified as hydrogels or organogels for water and organic solvent-containing materials, respectively.

Green chemistry was initially developed with organic synthesis and industrial chemical processes in mind. ${ }^{13}$ In comparison, sustainable approaches to the chemistry of metalorganic materials have emerged rather indirectly. Fig. 2b shows publications that include the term "green chemistry" alongside "coordination polymer" or "metal-organic frame-
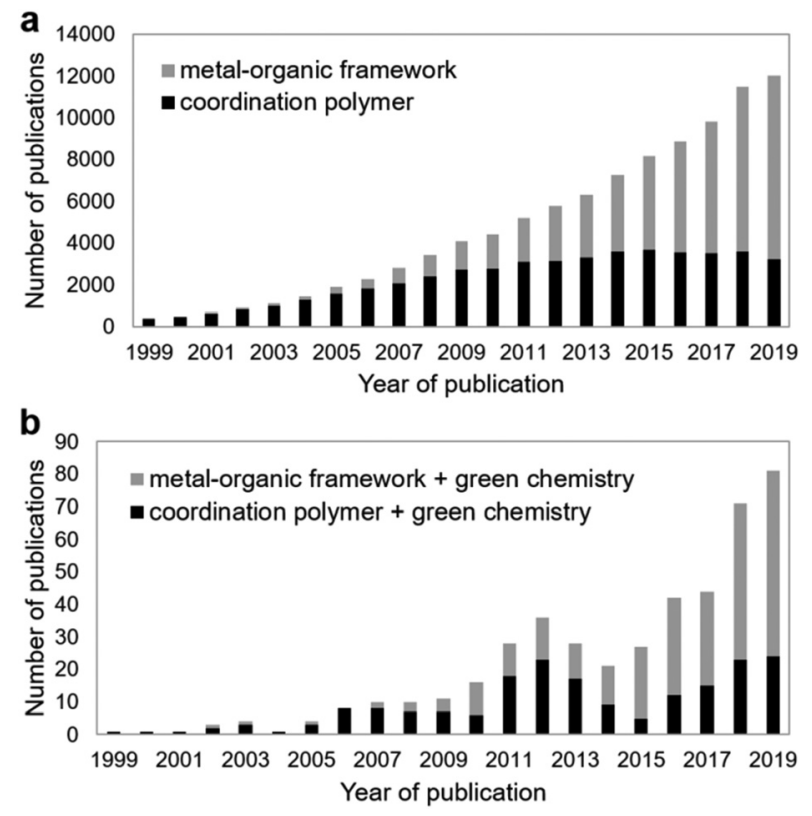

Fig. 2 Number of publications in a given year, for the period 1999-2019, mentioning the terms (a) "metal-organic framework" and "coordination polymer" and (b) "metal-organic framework" + "green chemistry" and "coordination polymer" + "green chemistry" by Web of Science search of topics, which entails a search of titles, abstracts and keywords.

work". There were only 81 such articles in 2019, which is a mere $0.7 \%$ of all CP and MOF articles published that year. Systematic, rigorous endeavours to develop the green chemistry of CPs have been limited, which may explain why progress in this area has been fragmented and sporadic. However, if CPs are to move from laboratory curiosities to functional materials enabling sustainable technologies a focus on green CP chemistry is critical.

Numerous applications have been proposed for CPs, including catalysis, ${ }^{14,15}$ gas capture, ${ }^{16,17}$ molecular separations ${ }^{18-21}$ and sensing. ${ }^{22,23}$ Given their wide-ranging potential, and considering the imperative to incorporate sustainability into the design of new materials, the development of green CPs is essential as are sustainable approaches to their preparation. An obvious approach would be to design CPs according to the 12 Principles of Green Chemistry. Despite this, an authoritative 1999 review "Green Chemistry: Challenges and Opportunities" contained no mention of CPs or metal-organic products. $^{24}$ Similarly, the 2009 review "Green Chemistry: Principles and Practice", included no references to CPs. ${ }^{25}$ Even recently, major aspects of green chemistry have been reviewed, ${ }^{26,27}$ where the authors did not cite any examples of metal-organic or CP materials. A number of reviews have addressed environmental sustainability and biocompatibility aspects of CPs. These have focussed on specific aspects, such as the green synthesis of well-known MOFs exclusively ${ }^{28}$ and ionic liquids and supercritical $\mathrm{CO}_{2}$ as green solvents in MOF synthesis. ${ }^{29}$ Friščić et al. have reviewed mechanochemistry as a 
green alternative to conventional solution-based synthesis of $\mathrm{CPs}^{30}{ }^{30}$ while Chen et al. addressed the green chemistry of MOFs in the context of sustainable catalysis. ${ }^{15}$ The prospects for application of MOFs in various "environmentally conscious applications" have been discussed by Ajoyan et al. ${ }^{31}$ Very recently, cyclodextrin-based MOFs, considered inherently sustainable, were covered by Rajkumar and co-workers. ${ }^{32}$ The present review is an attempt to consolidate advances in the green chemistry of CP materials in general.

In determining how "green" a CP material is, the following factors should be considered:

- What hazards are associated with the ligand? Ideally the ligand should be non-hazardous to the environment and to human health, and should not pose any safety risks (e.g. explosivity).

- Is the ligand obtainable from renewable and sustainable resources via green processes? Non-fossil fuel-based ligands are generally preferable.

- What hazards are associated with the metal ion? Ideally the metal ion should be non-hazardous to the environment and to human health, and should not pose any safety risks.

- How earth abundant is the metal? Earth abundant metals are preferred.

- Can the CP be prepared by a green chemistry procedure?

Sustainable approaches to the production and use of CPs span a variety of strategies. In this review we consider aspects of the most common strategies, including: (1) appropriate ligand selection; (2) appropriate metal ion selection; (3) solvent minimisation or the use of benign solvents and (4) specific techniques for green synthesis.

\section{Ligand selection}

CPs incorporate a variety of synthetic and naturally-occurring ligands. The earliest high surface area, thermally stable MOFs employed rigid ligands bearing carboxylate, imidazolate or pyridyl moieties, often incorporating aromatic groups or polyaromatic spacers. ${ }^{33}$ Such rigid aromatic ligands are usually fossil carbon-based and some may be harmful to humans and the environment, but are useful for preparing rigid 3D networks with permanent porosity and high internal surface areas. Engineering permanent porosity has been a major focus of MOF research; however, research on "soft porous crystals"34 has grown, where ligand flexibility and labile coordination bonds are of interest, and there remains huge potential for materials based on 1D and 2D CPs.

Naturally-occurring and bio-based ligands for CPs have received growing attention as green chemistry approaches have gained traction and as researchers have broken with the received wisdom that only rigid 3D MOFs have potential as new technologies. 'Green ligands' should be obtainable from renewable sources (e.g. biomass), and be environmentally benign and biodegradable, unless recycling of the CP is feasible. Among the most widely exploited are aliphatic diacids, amino acids and nucleobases. Beobide and co-authors have produced a useful review of metal-carboxylato-nucleobase architectures. ${ }^{44}$ Here we focus on selected aliphatic diacids, amino acids and cyclodextrins as examples of important green ligands (Table 1). We highlight a range of existing CPs based on these ligands to illustrate their utility. However, many of these examples incorporate unfavourable metal ions and would not be considered green CPs. A great deal more work is required to match sustainable ligands and metals. Metal ion selection will be discussed separately.

\section{Aliphatic diacids}

Key aliphatic diacids employed as green ligands in CP materials are shown in Fig. 3. The unsaturated linear aliphatic dicarboxylic acids are the series with general formula HOOC$\left[\mathrm{CH}_{2}\right]_{n}-\mathrm{COOH}$. Those that are readily available as commodity or fine chemicals range from the smallest, oxalic acid, with $n=$ 0 to hexadecanedioic acid, with $n=14$. Most are considered to be of low risk, are biodegradable and some are already available by fermentation from bio-based feedstocks as commodity chemicals. $^{36}$ Adipic acid and oxalic acid are important CP ligands that are candidates for industrial production by fermentation. Industrial fermentation processes for adipic acid production $^{36,37}$ are advanced as compared with fermentationbased oxalic acid, which is not yet commercially viable. ${ }^{41}$ Beyond the HOOC- $\left[\mathrm{CH}_{2}\right]_{n}-\mathrm{COOH}$ series, itaconic acid and 2,5furandicarboxylic acid are bio-based ligands that are produced at large scale and have been explored for the construction of CPs. Large quantities of itaconic acid are produced by fermentation. ${ }^{36,39}$ 2,5-Furandicarboxylic acid is obtainable from biomass at scale but not yet by green synthesis. ${ }^{40}$

Succinic acid. This compound is already commercially produced, via fermentation, at large scale and economically competitive rates. ${ }^{35}$ Its good water solubility ( $8.7 \mathrm{~g}$ per $100 \mathrm{~g}$ water at $298 \mathrm{~K}$ (ref. 45)) makes succinate CP synthesis in aqueous medium relatively straightforward and, as a CP ligand, succinate is associated with a large degree of structural diversity and a broad range of different metal centres.

Rare earth (mainly lanthanide) metal succinate CPs are particularly prevalent in literature and are well documented in the recent review by Bernini et al., which includes mixed ligand CPs. ${ }^{46}$ Worth noting are the Ho(III) succinate CPs prepared from succinylsalicylic acid, which was hydrolysed in situ ${ }^{47}$ and a broad series of lanthanide succinate CPs, including 2D architectures and 3D architectures with relatively large calculated solvent-accessible volumes, synthesised with 5-sulfosalicylate as templating agent. ${ }^{48}$ The near-infrared luminescence of lanthanide succinate and lanthanide $p$-toluylate-acetate CPs has been explored, with enhancement of luminescence noted for $p$-toluylate-acetate only, confirming that succinate itself tends not to contribute to electromagnetic properties. ${ }^{49}$

Of course, transition metal succinate CPs are also common. A Cu(II) succinate 1D CP, reported as a 3D framework based on hydrogen bonding, has been subjected to low temperature magnetic studies. ${ }^{50}$ Several Co(II) succinate CPs are known, with thirteen unique Cambridge Structural Database (CSD) entries at the time of writing containing $\operatorname{Co(II)}$ as the only 
Table 1 Selected important compounds employed as green ligands in CP synthesis

\begin{tabular}{|c|c|c|c|c|}
\hline Type & Ligand & Commercial availability & Safety & Comments \\
\hline \multirow[t]{5}{*}{$\begin{array}{l}\text { Aliphatic } \\
\text { diacids }\end{array}$} & Succinic acid & $\begin{array}{l}\text { Large scale production by } \\
\text { industrial fermentation } \\
\text { is,36 }\end{array}$ & $\begin{array}{l}\text { Readily biodegradable; causes } \\
\text { serious eye damage (H318) }\end{array}$ & $\begin{array}{l}\text { Good water solubility lends } \\
\text { itself to CP synthesis in } \\
\text { aqueous medium }\end{array}$ \\
\hline & Adipic acid & $\begin{array}{l}\text { Not yet available in large quantities } \\
\text { from bio-based production but } \\
\text { considerable research efforts are } \\
\text { underway }\end{array}$ & $\begin{array}{l}\text { Harmful to aquatic life but readily } \\
\text { biodegradable; causes serious eye } \\
\text { damage (H318) }\end{array}$ & $\begin{array}{l}\text { The leading industrial } \\
\text { aliphatic dicarboxylic acid } \\
\text { because of its use in Nylon } \\
6,6 \text { production }\end{array}$ \\
\hline & Itaconic acid & $\begin{array}{l}\text { Considered a niche commodity } \\
\text { chemical but available at large } \\
\text { scale via fermentation }\end{array}$ & $\begin{array}{l}\text { Harmful to aquatic life but readily } \\
\text { biodegradable; causes serious eye } \\
\text { damage (H318) }\end{array}$ & $\begin{array}{l}\text { Underexplored as a CP } \\
\text { ligand. Only limited } \\
\text { examples have been reported }\end{array}$ \\
\hline & $\begin{array}{l}2,5- \\
\text { Furandicarboxylic } \\
\text { acid }\end{array}$ & $\begin{array}{l}\text { A leading bio-based platform } \\
\text { chemical produced in very large } \\
\text { quantities from biomass but not } \\
\text { via green synthesis }\end{array}$ & $\begin{array}{l}\text { Readily biodegradable; causes } \\
\text { serious eye irritation (H319) }\end{array}$ & $\begin{array}{l}\text { Employed as a terephthalic } \\
\text { acid alternative because of its } \\
\text { structural similarity }\end{array}$ \\
\hline & Oxalic acid & $\begin{array}{l}\text { Large scale production from } \\
\text { biomass but not via green } \\
\text { synthesis }\end{array}$ & $\begin{array}{l}\text { Readily biodegradable; harmful if } \\
\text { swallowed (H302) or in contact } \\
\text { with skin (H312) and causes } \\
\text { serious eye irritation (H319) }\end{array}$ & $\begin{array}{l}\text { Mostly present in mixed } \\
\text { ligand CPs }\end{array}$ \\
\hline \multirow[t]{8}{*}{ Amino acids } & Aspartic acid & $\begin{array}{l}\text { Available from industrial enzymatic } \\
\text { methods }^{42}\end{array}$ & Not a hazardous substance & $\begin{array}{l}\text { Used in the production of } \\
\text { aspartame and polyaspartic } \\
\text { acid, a biodegradable } \\
\text { polymer }\end{array}$ \\
\hline & Glutamic acid & $\begin{array}{l}\text { The most important industrial } \\
\text { amino acid produced in very large } \\
\text { quantities as L-glutamate by } \\
\text { fermentation }{ }^{42}\end{array}$ & Not a hazardous substance & $\begin{array}{l}\text { Widely used as a food } \\
\text { additive }\end{array}$ \\
\hline & Phenylalanine & $\begin{array}{l}\text { Available from industrial } \\
\text { fermentation }^{42}\end{array}$ & Not a hazardous substance & $\begin{array}{l}\text { Used in nutritional } \\
\text { applications, such as } \\
\text { aspartame production }\end{array}$ \\
\hline & Cysteine & $\begin{array}{l}\text { Available from industrial enzymatic } \\
\text { methods }^{42}\end{array}$ & Harmful if swallowed (H302) & $\begin{array}{l}\text { Dimerises to cystine in } \\
\text { alkaline medium }\end{array}$ \\
\hline & Cystine & $\begin{array}{l}\text { Available from industrial enzymatic } \\
\text { methods }\end{array}$ & Not a hazardous substance & - \\
\hline & Histidine & $\begin{array}{l}\text { Available from industrial } \\
\text { fermentation }^{42}\end{array}$ & Not a hazardous substance & - \\
\hline & Tryptophan & $\begin{array}{l}\text { Available from industrial } \\
\text { fermentation and enzymatic } \\
\text { methods }^{42}\end{array}$ & Not a hazardous substance & - \\
\hline & Tyrosine & $\begin{array}{l}\text { Available from industrial } \\
\text { fermentation }^{42}\end{array}$ & Not a hazardous substance & - \\
\hline \multirow[t]{3}{*}{ Cyclodextrins } & $\alpha$-Cyclodextrin & $\begin{array}{l}\text { Large scale production by } \\
\text { enzymatic conversion }\end{array}$ & Not a hazardous substance & $\begin{array}{l}\text { Good water solubility: } \\
145 \mathrm{~g} \mathrm{~L}^{-1}\end{array}$ \\
\hline & $\beta$-Cyclodextrin & $\begin{array}{l}\text { Large scale production by } \\
\text { enzymatic conversion }\end{array}$ & Not a hazardous substance & $\begin{array}{l}\text { Poor water solubility: } \\
18.5 \mathrm{~g} \mathrm{~L}^{-1}\end{array}$ \\
\hline & $\gamma$-Cyclodextrin & $\begin{array}{l}\text { Large scale production by } \\
\text { enzymatic conversion }^{43}\end{array}$ & Not a hazardous substance & $\begin{array}{l}\text { Good water solubility: } \\
232 \mathrm{~g} \mathrm{~L}^{-1}\end{array}$ \\
\hline
\end{tabular}<smiles>C=C(CC(=O)O)C(=O)O</smiles>

Fig. 3 Important aliphatic diacids employed as green ligands, from left to right: oxalic acid, succinic acid, itaconic acid (2-methylenesuccinic acid), adipic acid and 2,5-furandicarboxylic acid.

metal and succinate as the only organic ligand (CSD reference codes: 221317, 830032, 620466, 138985, 257268, 157785, 161392, 165917, 268305, 830034, 156110, 1050327, 1050331).
Analysis of results of high throughput screening experiments showed that varying temperature, $\mathrm{pH}$, concentration and time of hydrothermal reactions could produce seven unique $\mathrm{Co}$ (II) succinate CPs, two of which were novel at the time. ${ }^{51}$ Reversible dehydration, where crystallinity is preserved, accompanied by colour change has been demonstrated for a $\mathrm{Co}$ (II) succinate CP. ${ }^{52}$ A systematic study of mixed metal succinates containing $\mathrm{Co}$ (II), $\mathrm{Fe}(\mathrm{II})$ and $\mathrm{Mn}$ (II) found evidence of partial ordering of the different metal cations across the crystallographic metallic nodes of the framework. ${ }^{53}$ In a separate mixed metal study, by varying the $\mathrm{Co} / \mathrm{Ni}$ ratio in the reaction mixture, four different metal succinate CP structures (including mixed metal CPs) were isolated from constant reaction conditions (Fig. 4). ${ }^{54}$ Unusual low temperature magnetic transitions were observed for a $\mathrm{Mn}$ (II) CP. ${ }^{55}$ However, while many succinates have been explored for their magnetic properties, 


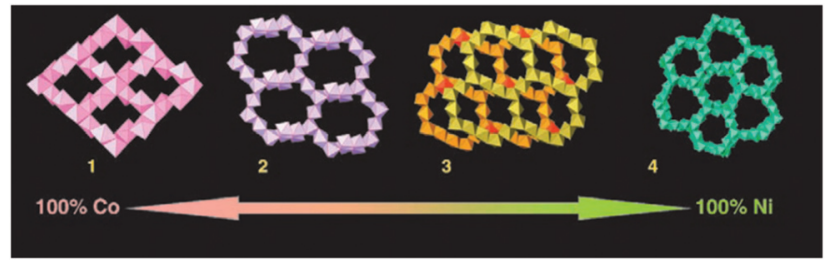

Fig. 4 Four crystal architectures of mixed metal succinates based on $\mathrm{Co}(I)$ and $\mathrm{Ni}(\mathrm{II})$, starting from Co succinate $\mathrm{CO}_{5}(\mathrm{OH})_{2}\left(\mathrm{C}_{4} \mathrm{H}_{4} \mathrm{O}_{4}\right)_{4}$ (1) with increasing substitution by $\mathrm{Ni}: \mathrm{M}_{4}(\mathrm{OH})_{2}\left(\mathrm{H}_{2} \mathrm{O}\right)_{2}\left(\mathrm{C}_{4} \mathrm{H}_{4} \mathrm{O}_{4}\right)_{3} \cdot 2 \mathrm{H}_{2} \mathrm{O}$ (2), $\mathrm{M}_{7}(\mathrm{OH})_{2}\left(\mathrm{H}_{2} \mathrm{O}\right)_{2}\left(\mathrm{C}_{4} \mathrm{H}_{4} \mathrm{O}_{4}\right)_{6} \cdot 3.5 \mathrm{H}_{2} \mathrm{O}$ (3), and $\mathrm{Ni}_{7}(\mathrm{OH})_{2}\left(\mathrm{H}_{2} \mathrm{O}\right)_{2^{-}}$ $\left(\mathrm{C}_{4} \mathrm{H}_{4} \mathrm{O}_{4}\right)_{6} \cdot 2 \mathrm{H}_{2} \mathrm{O}$ (4). Only the metal polyhedral are represented. Reprinted from ref. 54 with permission from John Wiley and Sons.

mostly modest results are reported. CPs based on Li, succinic acid, methyl succinic acid and malic acid were prepared by a solvent-free method. ${ }^{56}$ A rare example of an Ag(I)-based succinate CP was reported in $1993,{ }^{57}$ while spontaneous symmetry breaking was achieved to obtain a rare homochiral succinate CP with a uranyl metal centre. ${ }^{58}$

Adipic acid. It is the most important industrial aliphatic dicarboxylic acid (used in the preparation of Nylon 6,6) and significant research efforts are under way by various companies to develop processes for its production from bio-based feedstocks. ${ }^{36,37}$ Low yields have been a major drawback in the direct conversion of biomass to adipic acid. ${ }^{38}$ A number of CPs exist with adipic acid as the sole organic ligand. Employing $\mathrm{Mn}$ (II) as metal ion, Zheng et al. claimed discovery of the first adipate CP exhibiting possible ferroelectric properties. ${ }^{59}$ Another Mn(II) adipate CP, synthesised by a hydrothermal method, exhibits a 2D structure and antiferromagnetic behaviour below $15 \mathrm{~K}^{60} \mathrm{Ce}(\mathrm{III})$ adipate 3D CPs have been reported, where two slightly different networks were obtained by varying the reaction conditions. ${ }^{61}$ Other lanthanide adipate frameworks have been synthesised where 4,4'-bipyridine was required as a templating agent. ${ }^{62}$ Given that $4,4^{\prime}$-bipyridine is a common pillaring ligand in 3D CPs, it is likely that 4,4'-bipyridine was initially expected to be incorporated as a ligand within the $\mathrm{CP}$ product. Using the templating approach based on bipyridine, two $\mathrm{Ca}$ adipate CPs have also been synthesised. ${ }^{63}$ Uniaxial negative thermal expansion at low temperature has been reported for a $\mathrm{Co}(\mathrm{II})$-adipate $\mathrm{CP} .{ }^{64}$

Itaconic acid. Also referred to as 2-methylenesuccinic acid, it is available in large quantities via fermentation from at least 30 suppliers worldwide but is still considered a niche commodity chemical. ${ }^{36,39}$ However, it is far less prevalent than succinic acid as a component of CPs. At the time of writing there were only ten unique crystal structures in the CSD of CPs containing itaconic acid as the exclusive organic ligand (CSD reference codes: 1242584, 1251508, 1477388, 1477389, 1477391, 1532660, 1532661, 1532662, 1532663, 1045628). Li et al. have developed lanthanide-based CPs incorporating itaconic acid. ${ }^{65,66}$ Nair et al. synthesised a 2D Ca CP with itaconic acid as ligand. Remarkably, the compound is photoluminescent (Fig. 5), which is rare among Ca CPs. ${ }^{67}$ Mixed metal itaconic
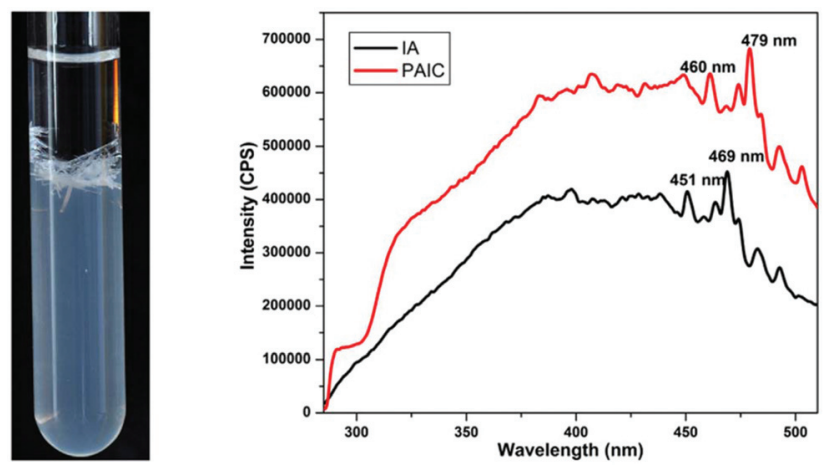

Fig. 5 Crystals of a luminescent $\mathrm{CP}$ based on $\mathrm{Ca}$ and itaconic acid, and solid state luminescence spectra of the ligand (IA) and CP (PAIC) at room temperature with $\lambda_{\max }=285 \mathrm{~nm}$. Reprinted from ref. 67 with permission from Elsevier.

acid CPs have been prepared by combining $\mathrm{Cu}(\mathrm{II})$ with different lanthanides, with a mixed $\mathrm{Cu}-\mathrm{Gd}$ itaconate $\mathrm{CP}$ exhibiting a large magnetocaloric effect, making it a potential material for low-temperature refrigeration applications. ${ }^{66}$

2,5-Furandicarboxylic acid. 2,5-Furandicarboxylic acid (FDC) is a versatile ligand for CP synthesis, and a leading bio-based platform chemical. It is produced in very large quantities from biomass but not yet via green synthesis. ${ }^{40}$ It is a possible alternative to terephthalic acid (1,4-dicarboxylic acid) because of its structural similarity.

By varying reaction conditions, non-porous $2 \mathrm{~mm}$-sized pale blue crystals and porous turquoise microcrystals of different $\mathrm{Cu}(\mathrm{II})$ FDC CPs have been synthesised. Alongside these, CP organogels of $\mathrm{Fe}(\mathrm{II}) \mathrm{FDC}$ and $\mathrm{Al}(\mathrm{III}) \mathrm{FDC}$ were also obtained. $^{68}$

A number of $\mathrm{Zn}$ (II) FDC CPs have been identified as potential drug delivery materials with evidence of nontoxicity. Aqueous stability and $17.9 \mathrm{wt} \%$ loading of the chemotherapy drug 5-fluorouracil has been demonstrated for a Zn(II) FDC 3D $\mathrm{CP}$ with rectangular channels, ${ }^{69}$ while for a different Zn(II) FDC 3D CP 22.5 wt\% encapsulation of 5-fluorouracil, along with selective $\mathrm{CO}_{2}$ sorption, was reported. ${ }^{70} 5$-Fluorouracil is of interest because its targeting of cancer cells may be improved by developing innovative controlled release drug delivery strategies. Recently a Zn(II) FDC 2D CP was been described exhibiting $11.4 \mathrm{wt} \% 5$-fluorouracil uptake. ${ }^{71}$

An unusual cage-within-cage structure based on $\mathrm{Zn}$ (II) and FDC was prepared by solvothermal synthesis ${ }^{72}$ and photoluminescent Zn(II) FDC CPs have been reported. ${ }^{73}$

Zhai et al. prepared several Mg-based MOFs, including one with FDC as linker, called CPM-203. Of the series of five MOFs tested for gas sorption capacity and selectivity, CPM-203 performed best with relatively high $\mathrm{CO}_{2}$ uptake of $53.1 \mathrm{~cm}^{3} \mathrm{~g}^{-1}$ at $273 \mathrm{~K}$ and $1 \mathrm{~atm}$, and negligible adsorption of $\mathrm{CH}_{4}$ under the same conditions. ${ }^{74}$

An impressive series of thirty-four different robust Fe-based CPs were synthesised by a rational approach using $\left[\mathrm{Fe}_{2} \mathrm{M}\left(\mu_{3}-\mathrm{O}\right)\right.$ $\left.\left(\mathrm{CH}_{3} \mathrm{COO}\right)_{6}\right]$ as starting material. ${ }^{76}$ Among these was PCN-233, 
based on $\mathrm{Fe}(\mathrm{III})$ and FDC, which is also described in a patent covering "iron metal organic framework materials". ${ }^{77}$

The formation of crown ether-type secondary building units based on $\mathrm{K}^{+}$and FDC was observed as part of an investigation of lanthanide FDC CPs. ${ }^{75}$ These unusual secondary building units resemble 16-crown-6 (Fig. 6) and 23-crown-9. The cationdependence of crown ether type metallolinkers based on FDC has been systematically investigated by Einkauf and coworkers. $^{79}$

Li et al. investigated two homo- and two heterometallic FDC CPs, based on Co(II), Gd(III) and Dy(III), including magnetic studies and photoluminescence studies. ${ }^{80}$ Three Sc(III) fumarate MOFs have been described by Barsukova et al. and one of these is thermally stable up to $300^{\circ} \mathrm{C}$ and remarkably hydrolytically stable in aqueous medium across the $\mathrm{pH}$ range $1-13 .^{81}$
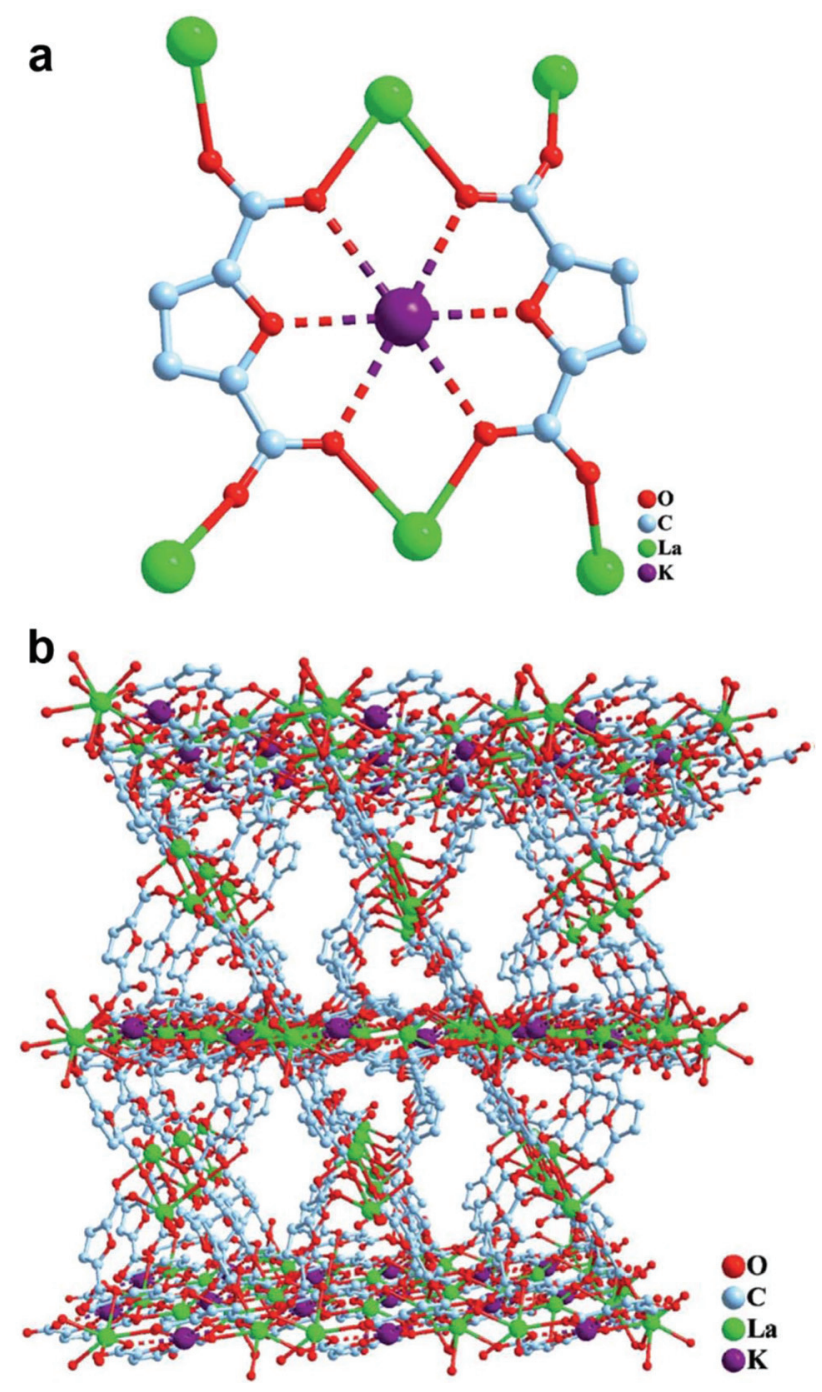

Fig. 6 Single-crystal X-ray structure of a 3D lanthanide FDC CP containing $\mathrm{K}^{+}$ions: (a) secondary building unit resembling 16-crown- 6 and (b) packing diagram viewed along [100]. Reprinted from ref. 75 with permission from John Wiley and Sons.
MIL-160 (Fig. 7) is an $\mathrm{Al}(\mathrm{III})$ FDC CP that can be prepared via scalable green synthesis by refluxing in aqueous medium and performs well as a potential water sorbent for heat exchange applications, with superior performance $313 \mathrm{~K}$ and $1.2 \mathrm{kPa}$ when compared with other important water sorbents. ${ }^{78}$ The crystal structure of MIL-160 has been established by synchrotron PXRD. ${ }^{82}$ The framework exhibits high water sorption capacity and potential use in heat exchange applications with its relatively high energy storage capacity of $343 \mathrm{~W} \mathrm{~h} \mathrm{~kg}^{-1} \cdot{ }^{78,83}$

Oxalic acid. This naturally-occurring compound has been used effectively to prepare a number of mixed ligand dicarboxylate CPs. A series based on $\mathrm{Nd}$, reported by Scales et al., included a succinate and a mixed succinate-oxalate $\mathrm{CP} .{ }^{84} \mathrm{~A}$ variety of other lanthanide CPs with FDC and oxalic acid as
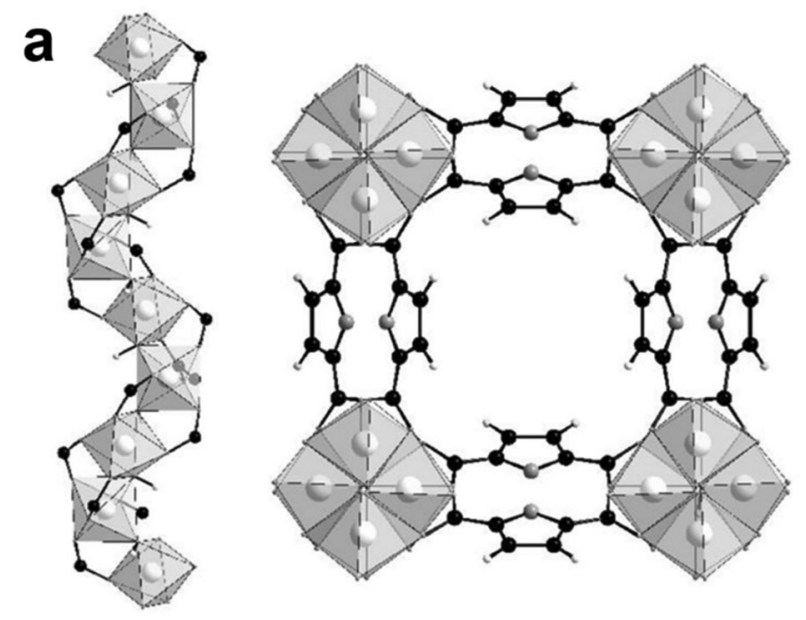

b

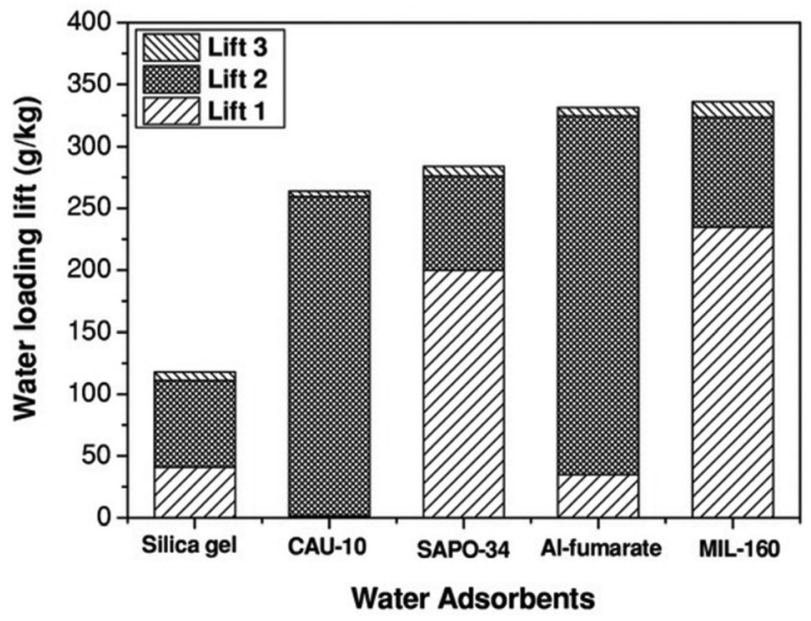

Fig. 7 MIL-160, an Al(III) FDC CP. (a) Partial X-ray single crystal structure of MIL-160 with C, $\mathrm{H}$ and $\mathrm{O}$ atoms represented in black, white and grey, respectively. (b) Gravimetric water loading (three "lifts" of different cycle conditions) for MIL-160 compared with other important water sorbents, showing superior sorption of MIL-160 under lift 1 conditions, $313 \mathrm{~K}$ and $1.2 \mathrm{kPa}$. Reprinted from ref. 78 with permission from John Wiley and Sons. 
ligands have been reported. ${ }^{85,86}$ Sadakiyo et al. achieved high proton conductivity in a $\mathrm{Zn}$ (II) FDC and oxalic acid-based CP incorporating $\mathrm{NH}_{4}{ }^{+}$ions as proton carriers. This was based on a strategy of incorporating proton carrying components of type I (counterions such as $\mathrm{NH}_{4}{ }^{+}, \mathrm{H}_{3} \mathrm{O}^{+}$or $\mathrm{HSO}_{4}{ }^{-}$), type II (protonated acidic ligands) and type III (acidic guest molecules) as a rational approach to the design of proton-conductive MOFs. ${ }^{87}$ These researchers went on to demonstrate control of proton conductivity by ion substitution; conductivity was reduced upon substitution of $\mathrm{NH}_{4}{ }^{+}$by $\mathrm{K}^{+}$, without changes in crystal structure. $^{88}$

\section{Amino acids}

Natural amino acids, the building blocks of proteins, are a potentially rich source of bio-based ligands. The amino acids represented in Fig. 8 have been important in CP synthesis and are available in varying quantities from industrial fermentation or enzymatic synthesis. L-Glutamic acid is the most important amino acid produced by industrial fermentation, as L-glutamate, at well over 3 million tons per year. ${ }^{42}$ By far the most widely explored amino acids for CP synthesis are the dicarboxylic acids aspartic acid and glutamic acid. Cysteine poses a challenge due to its propensity to dimerise in alkaline media, but its dimer, cysteine, is also structurally well-suited to CP formation. Phenylalanine, histidine, tyrosine and tryptophan have been employed to a lesser extent.

Chiral nanofibres of a $\mathrm{Cu}$ (II) aspartate CP (Fig. 9) can be prepared rapidly at room temperature by combining a solution of $\mathrm{Cu}\left(\mathrm{NO}_{3}\right)_{2}$ and alkaline solution of $\mathrm{L}^{-}$or D-aspartic acid. ${ }^{89}$ The authors refer to these nanofibres as "infinite CP particles", which readily form aqueous gels. At a minimum concentration of $0.07 \mathrm{M}$ of the reactants, $\mathrm{Cu}\left(\mathrm{NO}_{3}\right)_{2}$ and $\mathrm{L}^{-}$or D-aspartic acid, a<smiles>NC(CC(=O)O)C(=O)O</smiles><smiles>NC(CCC(=O)O)C(=O)O</smiles><smiles>NC(CC(=O)O)c1ccccc1</smiles><smiles>NC(CS)C(=O)O</smiles><smiles>NC(CSSCC(N)C(=O)O)C(=O)O</smiles><smiles>NC(Cc1c[nH]cn1)C(=O)O</smiles><smiles>NC(Cc1c[nH]c2ccccc12)C(=O)O</smiles><smiles>NC(Cc1ccc(O)cc1)C(=O)O</smiles>

Fig. 8 Important amino acids employed as green ligands, from left to right: aspartic acid, glutamic acid, phenylalanine, cysteine (dimerises to cystine in alkaline medium), cystine, histidine, tryptophan and tyrosine.
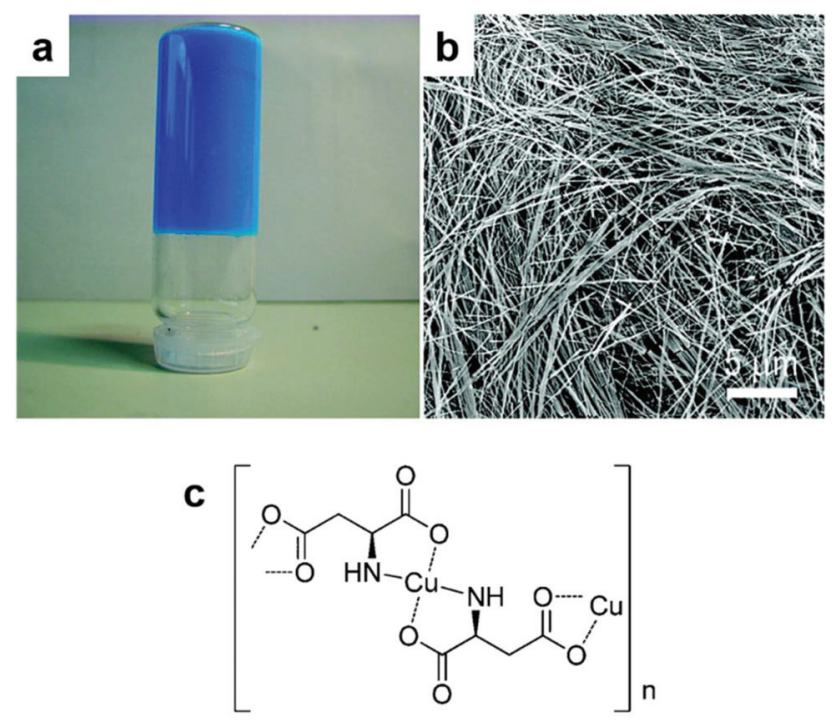

Fig. $9 \mathrm{Cu}(I)$-Aspartate chiral CP: (a) photograph of the CP aqueous gel, (b) FESEM image of the CP nanofibres and (c) proposed molecular structure of the CP. Reprinted with permission from ref. 89. Copyright (2009) American Chemical Society.

blue aqueous gel was formed; the gel remained stable for months at ambient temperature. $\mathrm{Cu}(\mathrm{II})$ and racemic glutamic acid have also been shown to form CP nanofibres from aqueous solutions at room temperature. When $\mathrm{Cu}$ (II) was combined with enantiomerically pure glutamic acid, nanoparticles of varying morphologies were obtained. However; employing racemic glutamic acid as ligand produced relatively uniform nanofibres, regardless of whether the metal source was $\mathrm{Cu}\left(\mathrm{NO}_{3}\right)_{2}, \mathrm{CuSO}_{4}$ or $\mathrm{CuCl}_{2}$. Sorption of Congo red from aqueous solutions and anti-bacterial properties have been demonstrated for this $\mathrm{Cu}$ (II) glutamate $\mathrm{CP} .{ }^{90}$ In a later publication, authors described the effect of stereochemistry on the rate of self-assembly of the $\mathrm{Cu}$ (II) aspartate and $\mathrm{Cu}($ II) glutamate nanofibres along with a new material, $\mathrm{Cu}$ (II) aminoadipate. The presence of both enantiomers of aspartic acid reduced the rate of self-assembly of the $\mathrm{Cu}$ (II) aspartate $\mathrm{CP}$ compared to the single enantiomer system. As ligand, DL-aspartic acid resolved to form a mixture of chiral CP crystallites of opposite handedness. Achiral nanofibre crystallites were formed when $\mathrm{Cu}$ (II) was combined with DL-glutamic acid at ligand concentrations below $0.35 \mathrm{mM}$, while plate-shaped microcrystals were obtained at ligand concentrations above $0.35 \mathrm{mM}$. Aqueous gels of this $\mathrm{Cu}(\mathrm{II})$-glutamate could be prepared at relatively high concentrations $(280 \mathrm{mM})$ based on the plate-shaped microcrystals but these gels were weak, and were easily disassembled by agitation. ${ }^{91}$

$\mathrm{Cu}(\mathrm{II})$ also forms chiral CPs and stereochemicallydependent aqueous gels with $\mathrm{D}^{-}$and L-phenylalanine. ${ }^{92}$ The enantiomeric ratio affects the kinetics of CP self-assembly and gelation. As in the case of $\mathrm{Cu}(\mathrm{II})$ L-adipate and $\mathrm{Cu}$-D-adipate, the presence of both enantiomers of phenylalanine inhibits $\mathrm{CP}$ self-assembly. The $\mathrm{Cu}(\mathrm{II})$ D-phenylalanine and $\mathrm{Cu}(\mathrm{II})$ 
L-phenylalanine CPs have a minimum gelator concentration of $0.35 \mathrm{wt} \%$ in water. Phenylalanine CP nanofibres have also been prepared at room temperature by combining an aqueous solution of $\mathrm{Zn}\left(\mathrm{NO}_{3}\right)$ with an aqueous alkaline solution of the enantiopure ligand. ${ }^{93}$ The nanofibres of $\mathrm{Zn}$ (II) D-phenylalinine and Zn(II)-L-phenylalanine were approximately 700-900 $\mathrm{nm}$ in diameter, hundreds of micrometers in length and appeared, from SEM images, to have smooth surfaces. When $\mathrm{Zn}\left(\mathrm{NO}_{3}\right)_{2}$ was combined with racemic phenylaniline, self-assembly resulted in plate-shaped microcrystals. Unfortunately, these nanofibres and microcrystals have typically been too small to allow for the elucidation of single-crystal X-ray structures.

Self-assembly of $\mathrm{Ag}(\mathrm{I})$ with enantiomerically pure cysteine yields fibrous "nanobelts" with right- (L-cysteine) and lefthanded (D-cysteine) helicity (Fig. 10), while the reaction of $\mathrm{Ag}(\mathrm{I})$ with racemic cysteine gives rise to two-dimensional achiral nanosheets. ${ }^{94}$ While the authors have represented the ligand as cysteine, the CP self-assembly reactions were carried out in alkaline medium and cysteine is well-known to be highly susceptible to oxidative dimerisation to cystine under such conditions. Elsewhere $\mathrm{ZnCl}_{2}$ and $\mathrm{L}$-cystine were combined in aqueous solution to yield well-defined spherical microspheres (Fig. 12). The size and morphology of the crystalline particles was concentration dependent: mixing $1 \mathrm{mM} \mathrm{ZnCl}_{2}$ and $1 \mathrm{mM}$ L-cystine at pH 8 produced microspheres of $5 \mu \mathrm{m}$ diameter, made up of rod-like crystallites of $50 \mathrm{~nm}$ in width and $200 \mathrm{~nm}$ in length. These $\mathrm{Zn}$ (II) cystine particles were developed into hybrid microspheres by incorporating a porphyrin (TTPS) and alcohol dehydrogenase (ADH). The $\mathrm{Zn}(\mathrm{II})$ cystine/TTPS/ADH microspheres exhibit a combination of photocatalytic and biocatalytic activity that mimics the photosynthetic activity of chloroplasts. Replacing Zn(II) with other divalent transition metals yielded alternative morphologies. ${ }^{95}$

Histidine-metal coordination (specifically imidazolatemetal coordination) has been exploited towards developing materials with self-healing properties because of the reversible nature of histidine-metal coordination bonds. These materials have typically been metallopolymers, not classic CPs. ${ }^{96}$ Metallopolymers comprise long organic polymer chains interspersed by coordinated metal ions. Antimicrobial activity was demonstrated for an $\mathrm{Ag}(\mathrm{I})$-histidine coordination compound where meso-form $\mathrm{D}-\mathrm{D}$ and $\mathrm{L}-\mathrm{L}$ dimer units are connected via silver-silver interactions. ${ }^{97}$ This is also strictly not a CP but the material is of interest because it exhibited antimicrobial activity and was prepared at room temperature by simple slow diffusion of aqueous solutions of D-histidine and L-histidine silver complexes. During the same study an Ag(I) D-histidine silver 1D CP (mirror image of the previously reported L-version ${ }^{98}$ ) was also obtained from aqueous self-assembly at room temperature.

L-Tyrosine, L-histidine, L-tryptophan and L-glutamic acid were combined with $\mathrm{Co}(\mathrm{II})$ and $\mathrm{Zn}$ (II) to prepare homochiral CP stationary phases for HPLC enantiomeric separations. ${ }^{99}$ Satisfactory resolution of a variety of organic small molecule enantiomers was achieved (Fig. 11). MOF-1 and MOF-6, based on $\mathrm{Zn}(\mathrm{II})$ and $\mathrm{Co}(\mathrm{II})$, respectively, with only amino acids as

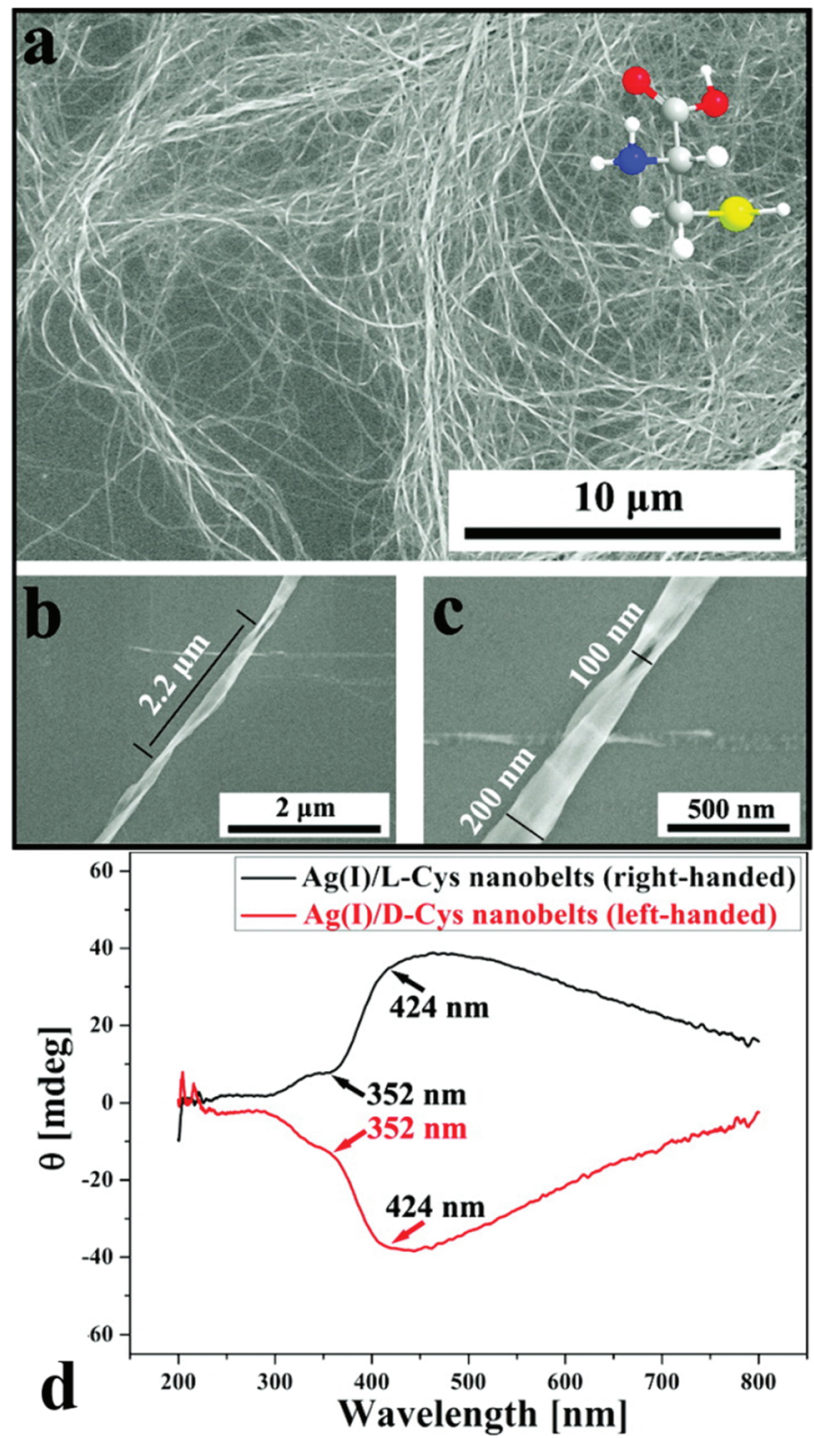

Fig. 10 Self-assembled $\mathrm{Ag}(\mathrm{I})$ cysteine helical "nanobelts" with homochirality: (a) large-area SEM image and (b, c) high-resolution SEM image of the right-handed (L-cysteine) version. (d) Circular dichroism spectra for the right-handed (L-cysteine) and left-handed (D-cysteine) versions. Reprinted with permission from ref. 94. Copyright (2010) American Chemical Society.

ligands and where the amino acids act as bridging ligands, were found to outperform the other MOFs, where the amino acids were coordinated as end groups. In a separate study of CP-based enantiomeric separations, a Cu(II) 3D CP was synthesised with the tripeptide Gly-L-His-Gly (GHG) as ligand, in ethanol at room temperature. ${ }^{100}$ Methamphetamine and ephedrine were chosen as model compounds for HPLC separation because of their prevalence in clinical research, forensics and toxicology. With the $\mathrm{Cu}$ (II) GHG CP as stationary phase, more efficient separation was achieved for ephedrine, by trapping of (+)-ephedrine, than for methamphetamine. The HPLC results were consistent with Monte Carlo simulations, where the cal- 

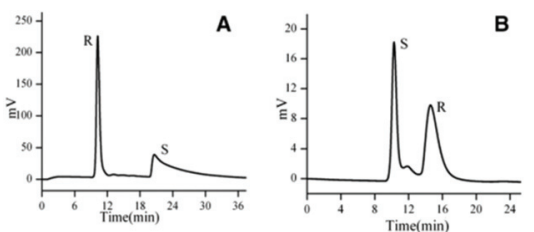

B
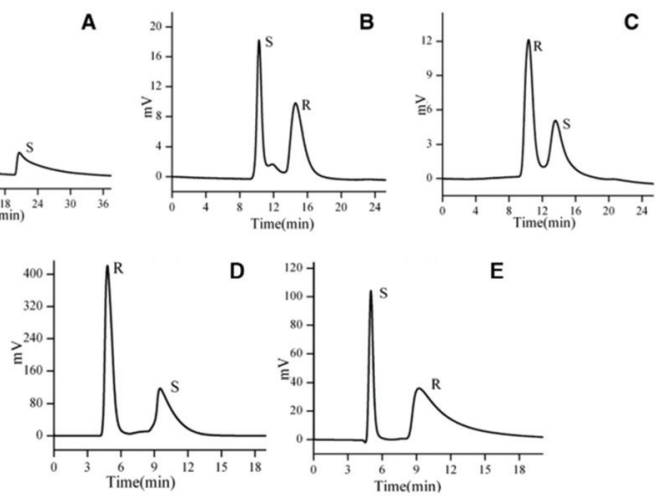

Fig. 11 Representative chromatograms showing effective chiral resolution on MOF-based HPLC columns. (A-C) Chromatograms for 1,2diphenyl-1,2-ethanediol, praziquantel and propranolol, respectively, obtained on a column with MOF-1, based on $\mathrm{Zn}(\mathrm{II})$ and L-tyrosine, as stationery phase. (D-E) Chromatograms for 1,2-diphenyl-1,2-ethanediol and chlorprophenpyridamine obtained on a column with MOF-6, based on Co(II) and L-glutamic acid, as stationery phase. MOF-1 and MOF-6 were judged to have outperformed the other 4 MOFs tested. Reprinted from ref. 99 with permission from John Wiley and Sons.

culated adsorption energy was greatest for the (+)-ephedrine enantiomer. Previous work had explored the sponge-like "amorphous-to-crystalline" sorption behaviour of $\mathrm{Cu}(\mathrm{II})-$ GHG and a similar porous CP based on $\mathrm{Cu}(\mathrm{II})$ and Gly-L-His-LLyc. ${ }^{101}$
A number of other CPs based on transition metals with aspartic acid ${ }^{102-105}$ or glutamic acid ${ }^{106,107}$ as ligand are known but, beyond crystallographic analysis, most of these materials have not been extensively investigated, suggesting a possible rich seam for future exploration.

\section{Cyclodextrins}

Cyclodextrins (CDs) are naturally-occurring cyclic oligosaccharides that have been used extensively in pharmaceutical industry, as well as in household cleaning products, agrochemical formulations and molecular separations. ${ }^{108}$ The readily available native CDs are $\alpha-, \beta$ - and $\gamma$-CD, comprising 6, 7 and $8 \alpha$-Dglucopyranoside units, respectively. Aqueous solubility is an important consideration in the use of native CDs as ligands. $\alpha$-CD and $\gamma$-CD have good water solubilities of $232 \mathrm{~g} \mathrm{~L}^{-1}$ and $145 \mathrm{~g} \mathrm{~L}^{-1}$, respectively, but the aqueous solubility of $\beta$-CD is much lower at $18.5 \mathrm{~g} \mathrm{~L}^{-1.43}$

Cyclodextrin-based MOFs (CD-MOFs) are based on the native cyclodextrins as green ligands with alkali metals as metallic nodes. The first CD-MOFs were based on $\gamma$-CD with $\mathrm{Na}, \mathrm{K}, \mathrm{Rb}$ and $\mathrm{Cs}$. They were referred to as CD-MOF-1 ( $\mathrm{K}$ and $\gamma$-CD), CD-MOF-2 (Rb and $\gamma$-CD) and CD-MOF-3 (Cs and $\gamma$-CD), their single-crystal X-ray crystal structures were elucidated (Fig. 13) and it was emphasised that the potassium version could be prepared from edible natural products. ${ }^{109}$ The synthesis of CD-MOF-1 and CD-MOF-2 has been improved upon and single-crystal X-ray structures for new $\gamma$-CD-MOFs based on $\mathrm{NaOH}$ and $\mathrm{SrBr}_{2}$ metallic nodes as well as a polymorph a)

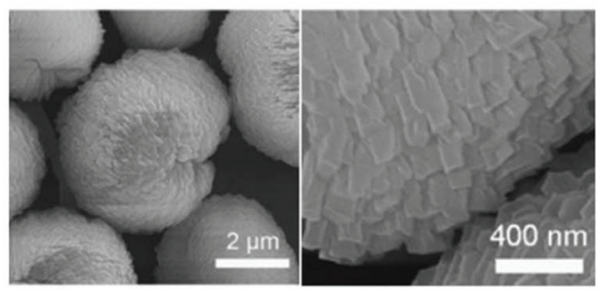

b)

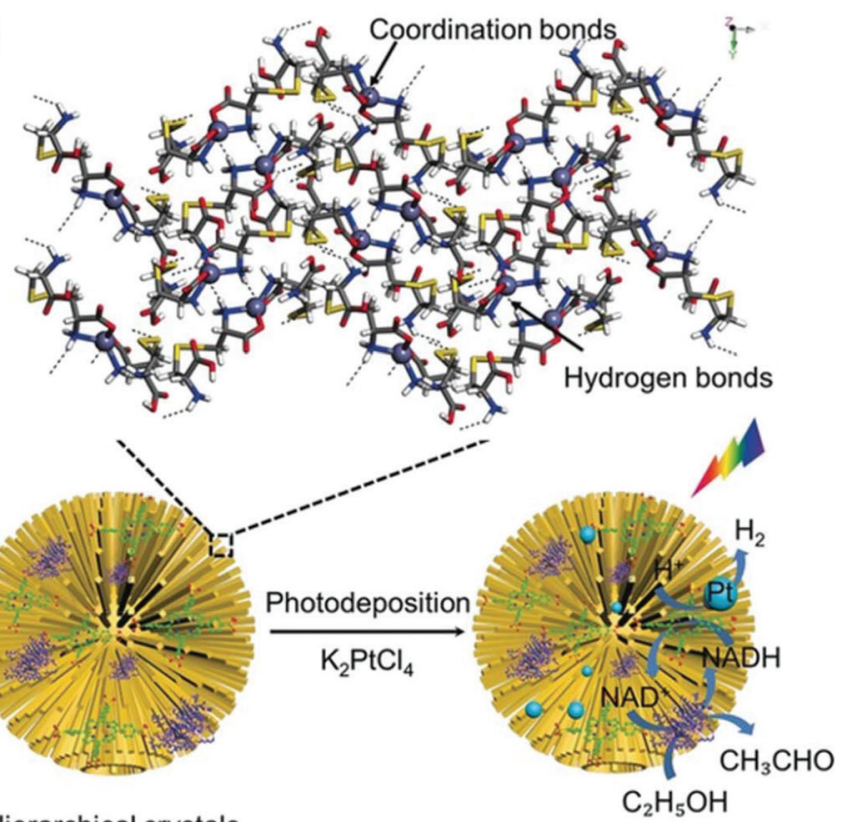

Hierarchical crystals

with incorporation

of porphyrin and enzyme

Chloroplast mimic

Fig. 12 Zn(II) cystine CP microspheres: (a) SEM images. (b) Suggested molecular packing based on density functional theory geometry optimisation and crystal structure refinement from powder X-ray diffraction. (c) Schematic representation of the hierarchical chloroplast mimics, prepared by self-assembly of the CP microspheres, followed by encapsulation of porphyrin and enzyme molecules for photoenzymatic reactions. Reprinted from ref. 95 with permission from John Wiley and Sons. 

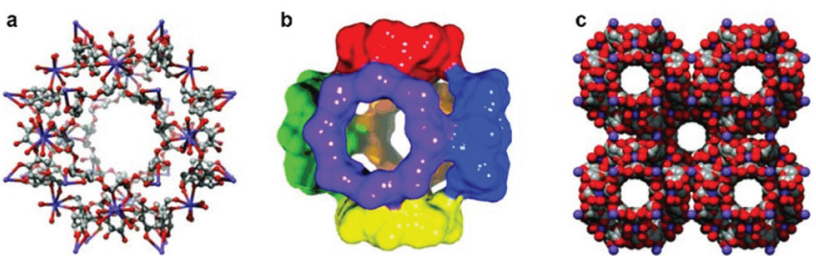

Fig. 13 Single-crystal $X$-ray structure representations of the first reported $C D-M O F$, based on $K$ and $\gamma-C D$. (a) Ball-and-stick representation of the cubic $(\gamma-C D)_{6}$ repeating motif ( $C$ grey, $O$ red, $K$ purple). (b) Cuboidal orientation of the six $\gamma-C D$ tori, illustrating the $1.7 \mathrm{~nm}$ sized pore at the centre of each $(\gamma-C D)_{6}$ repeating motif, where $\mathrm{K}^{+}$ions have been omitted for clarity. (c) Space-filling representation of the extended solid-state structure, with body-cantered cubic packing arrangement (C grey, O red, K purple). Reprinted from ref. 109 with permission from John Wiley and Sons.

comprising Cs and $\gamma$-CD have since been reported. ${ }^{110}$ After the original publications involving $\gamma$-CD exclusively, the first $\alpha$-CD-MOF was discovered in 2012, exhibiting chiral helices, and crystallising as hollow needles. ${ }^{111}$ The first $\beta$-CD-MOF was then reported in $2015 .{ }^{112}$ Subsequently, Sha and co-workers reported two $\beta$-CD-MOFs ${ }^{113}$ and one $\alpha$-CD-MOF, ${ }^{114}$ which are the first examples crystallising in the monoclinic space group.

The CD-MOFs typically encapsulate small hydrophobic organic molecules without alteration of the overall MOF crystal structure. Encapsulation of curcumin from a methanol solution was demonstrated by UV-vis spectrophotometry. ${ }^{115}$ Formaldehyde capture from air by a CD-MOF based on $\mathrm{K}$ and $\gamma$-CD has been achieved with a nine-fold improvement in adsorption capacity and rate of adsorption over activated carbon. ${ }^{116}$ CD-MOFs have already been extensively explored for pharmaceutical applications. ${ }^{117}$ As potential drug delivery materials, CD-MOFs have been used to encapsulate the chemotherapy drug 5-fluorouracil. Examples of $\mathrm{Na}^{-}$and $\mathrm{K}-\gamma$-CD-MOFs, and an Na- $\alpha$-CD-MOF have been reported with 5 -fluorouracil incorporated as guest molecule. ${ }^{113,118}$

The CD-MOFs are typically soluble in water; the ligand and metal cation readily dissociate when exposed to moisture but their moisture stability has been improved by the functionalisation of crystal surfaces by covalent grafting of cholesterol. The cholesterol-grafted CD-MOF crystals largely maintained morphological integrity and crystallinity even after immersion in water for $24 \mathrm{~h}$. However; microporosity was compromised, with a reduction in almost $50 \%$ in BET surface area for the cholesterol-grafted material as compared with the unmodified CD-MOF. ${ }^{119}$

Holcroft et al. have demonstrated the versatility of CD-MOF-1 (K and $\gamma$-CD) and CD-MOF-2 (Rb and $\gamma$-CD) for separating mixtures of BTEX (benzene, toluene, ethylbenzene and xylene isomers), regioisomers of ethyltoluene and cymene, and the purification of cumene. ${ }^{120}$ Hartlieb et al. extended molecular separations using CD-MOFs to a wide variety of organic mixtures, including ethylbenzene from styrene, haloaromatics, terpinenes, pinenes and other chiral compounds. ${ }^{121}$

\section{Metal ion selection}

When considering the choice of metal ions for construction of CPs, a number of factors could be important. In general, nontoxic, earth abundant metals are preferred. However, the "green" credentials of CPs can depend significantly on the application of the material. For example, use of a CP that is an effective $\mathrm{CO}_{2}$ sorption material, facilitating carbon capture and storage (or even transformation into useful chemicals, if it is also a catalyst), may provide significant sustainability gains, even if the metal salt starting material, or the synthesised CP, exhibits some mammalian toxicity when ingested. In such a bulk application, where the CP is contained and recoverable, effective recovery and recycling strategies, keeping the metal ions and ligands in use in keeping with the concepts of the Circular Economy, may mitigate any potential hazards associated with toxicity and provide a suitable sustainable technology. Earth abundant metals in chemistry are most frequently discussed in the context of organometallic catalysis, ${ }^{122}$ but the wider concepts of "critical" metals (and metalloids) ${ }^{123}$ should also be considered when designing and building new CPs. In this more considered analysis, "earth abundance" proves to be a good proxy for the critical factors defining metals of highest concern; metals that are: derived as by-products from production of others; used in small quantities and in highly specialised applications, and possessing no effective substitutes. ${ }^{123}$ Metal salts are usually the source of metal ions for CP synthesis and the counterions of these reagents should be chosen to minimise safety and toxicity problems. Nitrates and perchlorates should generally be avoided because of the potential for explosive oxidation under certain conditions. ${ }^{28}$ Further, if these materials are to be prepared industrially in large quantities, metal salt anions that are removed during the process, constitute a source of waste and thus, avoidance of large molecular weight and/or waste stream contaminating anions is advised.

As with all "wicked" problems, complex interdependencies make simple analysis impossible and almost always contextdependent. Full coverage of selection of "green" metal ion building blocks and starting salts for CP construction would require an extensive analysis of source (including energy costs and pollution resulting from mining and refining), in-use hazards and end-of-life fate, so here we confine ourselves to representative examples (Table 2). To avoid the use of terms that such as "heavy metal" that are poorly defined and can lead to confusion ${ }^{124}$ we group metal ions based on the position of the metal in the periodic table only. Certain CPs mentioned in this section would not be considered green CP systems because of ligand or synthesis failures but are mentioned to highlight the potential versatility of these favourable metal ions.

\section{s-Block}

While the low formula weight alkaline metal- and alkaline earth metal-based CPs are attractive from a green chemistry perspective, frequently these CPs exhibit poor aqueous and 
Table 2 Selected metal ions that are important in the development of green $\mathrm{CP}$ materials

\begin{tabular}{|c|c|c|c|}
\hline Type & $\begin{array}{l}\text { Metal } \\
\text { ion }\end{array}$ & Earth abundance $^{a} 125,126$ & Notable CPs \\
\hline $\begin{array}{l}\text { s- } \\
\text { Block }\end{array}$ & $\mathrm{Ca}^{2+}$ & $\begin{array}{l}\text { Calcium is the } 5^{\text {th }} \text { most } \\
\text { abundant element }\end{array}$ & $\begin{array}{l}\text { MOF-1201 and } \\
\text { MOF-1203; } \\
\text { BioMIL-4; }{ }^{128} \mathrm{Ca} \\
\left(\mathrm{H}_{2} \mathrm{O}\right)_{3}\left(\mathrm{H}_{2} \mathrm{PXBP}\right)^{129}\end{array}$ \\
\hline & $\mathrm{Mg}^{2+}$ & $\begin{array}{l}\text { Magnesium is the } 7^{\text {th }} \\
\text { most abundant element }\end{array}$ & Mg-MOF-74 \\
\hline \multirow[t]{4}{*}{$\begin{array}{l}\text { d- } \\
\text { Block }\end{array}$} & $\mathrm{Fe}^{3+}$ & $\begin{array}{l}\text { Iron is the } 3^{\text {rd }} \text { most } \\
\text { abundant element }\end{array}$ & 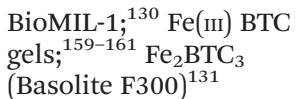 \\
\hline & $\mathrm{Zn}^{2+}$ & $\begin{array}{l}\text { Zinc is present in } \\
\text { moderate abundance but } \\
\text { is heavily mined and } \\
\text { there is some concern } \\
\text { about resource depletion }\end{array}$ & $\begin{array}{l}\text { MOF- } 5 ;^{132} \mathrm{Zn}(\mathrm{II}) \text { dicar- } \\
\text { boxylate catalysts; }{ }^{133} \mathrm{Zn} \\
\text { (II) cystine/guanine } \\
\text { microparticles }{ }^{134}\end{array}$ \\
\hline & $\mathrm{Ti}^{4+}$ & $\begin{array}{l}\text { Titanium is the } 8^{\text {th }} \text { most } \\
\text { abundant element }\end{array}$ & MIP-207 135 \\
\hline & $\mathrm{Zr}^{4+}$ & $\begin{array}{l}\text { Zirconium is moderately } \\
\text { abundant but not easily } \\
\text { accessible compared to } \\
\text { other ores }\end{array}$ & $\begin{array}{l}\text { UiO- } 66 ; ;^{136} \text { UiO-66- } \\
\mathrm{NO}_{2}{ }^{137}\end{array}$ \\
\hline $\begin{array}{l}\text { p- } \\
\text { Block }\end{array}$ & $\mathrm{Al}^{3+}$ & $\begin{array}{l}\text { Aluminium is the most } \\
\text { earth abundant metal }\end{array}$ & MIL-160 ${ }^{78}$ \\
\hline
\end{tabular}

${ }^{a}$ Abundance in the earth's crust, ignoring $\mathrm{O}$ and $\mathrm{H}$.

thermal stability. However, a number of remarkably stable Ca CPs have been discovered.

Calcium. Ca is the $5^{\text {th }}$ most common element in the earth's crust and in seawater (discounting $\mathrm{O}$ and $\mathrm{H}$ ) occurring most commonly as the various calcium carbonate minerals. ${ }^{126}$ It is also a key element in the human body, where it forms the major constituent of bone, and is widely used in food and medicine.

Single-crystal X-ray crystal structures were reported for isoskeletal CPs of Ca adipate monohydrate, ${ }^{138}$ Ca glutarate monohydrate $^{139}$ and Ca succinate monohydrate ${ }^{140}$ without investigation of possible functional properties. Ca succinate 2D CP crystals were prepared by hydrothermal synthesis and were "washed repeatedly with distilled water", suggesting these are not readily water soluble. ${ }^{141}$ De Lill et al., achieved remarkable synthesis of 3D Ca adipate CPs for which the crystals were washed with water (possibly water stable), possessing infinite channels occupied by the templating agent $4,4^{\prime}$-bipyridyl or 4,4'-bipyridylethane. ${ }^{63}$

$\mathrm{Ca}_{14}(\mathrm{~L} \text {-lactate })_{20}$ (acetate $)_{8}\left(\mathrm{C}_{2} \mathrm{H}_{5} \mathrm{OH}\right)\left(\mathrm{H}_{2} \mathrm{O}\right) \quad$ designated MOF-1201 and $\mathrm{Ca}_{6}(\mathrm{~L} \text {-lactate })_{3}(\text { acetate })_{9}\left(\mathrm{H}_{2} \mathrm{O}\right)$ designated MOF-1203, ${ }^{127}$ have been demonstrated to encapsulate and slowly release the agricultural fumigant cis-1,3-dichloropropene (DCP) used as a pesticide in a wide range of crops. DCP contained in MOF-1201 was released at a rate 100 times slower than from the liquid and the MOF hydrolyses in water making it a degradable solid carrier. Here the use of both metal ion and linker that are acceptable when distributed onto agricultural lands is key and the potential for reduction of worker exposure to the fumigant an improvement on current practice (the US permissible exposure level for DCP is $1 \mathrm{ppm}) .{ }^{142}$
Further MOF-1201 was synthesised in ethanol making all organic components potentially bioderived from renewable sources. MOFs 1201 and 1203, along with another MOF based on Zn(II), L-lactic acid and terephthalic acid, have since been prepared from polylactic acid, as part of a strategy for upcycling polylactic acid waste. ${ }^{143}$

The incorporation of biocompatible linkers and $\mathrm{Ca}^{2+}$ ions allows construction of "biomineralisation" agents for potential restoration of bone. A MOF with formula $\mathrm{Ca}\left(\mathrm{H}_{2} \mathrm{O}\right)_{3}\left(\mathrm{H}_{2} \mathrm{PXBP}\right)$, where PXBP is $p$-xylylenebisphosphonate, was described as nontoxic and able to stimulate in vitro bone formation. ${ }^{144}$ Generation of mixed cation $\mathrm{Sr}^{2+} / \mathrm{Ca}^{2+}$ forms of the MOF, in hydrothermal syntheses, allowed control of the rate of dissolution in simulated body fluids (Fig. 14). ${ }^{129}$

Building on many reports of MOFs able to separate, to varying degrees, light hydrocarbons such as $\mathrm{C}_{2} \mathrm{H}_{2} / \mathrm{C}_{2} \mathrm{H}_{4}$ and $\mathrm{C}_{2} \mathrm{H}_{4} / \mathrm{C}_{2} \mathrm{H}_{6}$, Li et al. described a calcium squarate MOF, synthesised in water from $\mathrm{CaCO}_{3}$ and squaric acid. ${ }^{145}$ The air stable and water stable product exhibited 1D channels that effectively "sieved" light $\mathrm{C} 2$ hydrocarbons with good adsorption selectivity of 8.1 for a $\mathrm{C}_{2} \mathrm{H}_{2} / \mathrm{C}_{2} \mathrm{H}_{4}$ mixture $(50: 50, \mathrm{v} / \mathrm{v})$.

In a food-based application, a Ca fumarate CP (described as a MOF although no structural data was provided), prepared from $\mathrm{Ca}$ acetate and fumaric acid in water, was shown to absorb fluoride ions from brick tea, offering a potential treatment to reduce the risk of fluorosis from this source. ${ }^{146}$

A Ca glutarate CP was denoted BioMIL-2 and crystal structures of both the anhydrous and hydrate versions have been elucidated. ${ }^{147}$ The authors classified glutaric acid as therapeutically active based on its status as an "experimental drug". The anhydrous phase is a 3D CP and was the first example of a Ca CP exhibiting permanent porosity, demonstrated by $\mathrm{N}_{2}$ sorption. Upon hydration, the $3 \mathrm{D}$ porous phase transforms to a non-porous " $1 \mathrm{D}$ inorganic sub-network phase". BioMIL-3 is based on $\mathrm{Ca}$ and 3,3',5,5'-azobenzenetetracarboxylate as ligand. The ligand is expected to be biocompatible and exhibit antimicrobial activity, as is common among azobenzene compounds, and the CP has been investigated for controlled deliv-
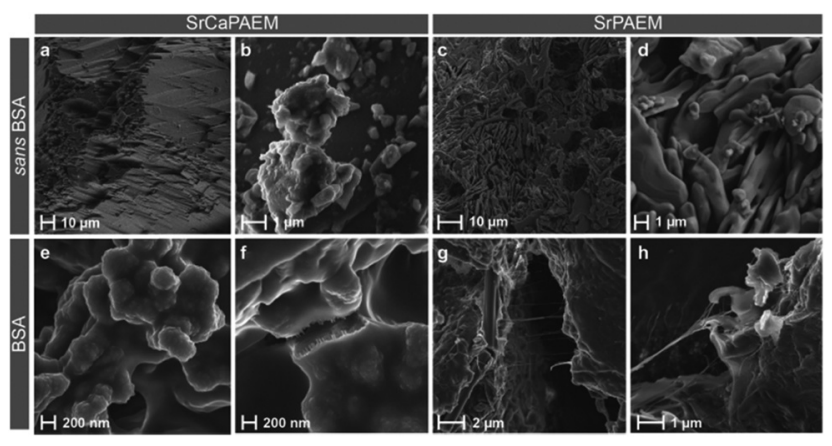

Fig. 14 SEM images of the $\mathrm{Sr}^{2+} / \mathrm{Ca}^{2+} \mathrm{CPs}$ SrCaPAEM and SrPAEM pre$(a-d)$ and post treatment $(e-h)$ with bovine serum albumin. The smoother edges and fibre-like features in e- $\mathrm{h}$ are indicative of adsorption of the BSA protein. Reprinted with permission from 129. Copyright (2019) American Chemical Society. 
ery of NO under biologically relevant conditions. ${ }^{148}$ BioMIL-4 is also based on $\mathrm{Ca}$, incorporates alendronate as ligand and was synthesised hydrothermally. ${ }^{128}$ Alendronate is a bisphosphonate that has been used in the treatment of various bone diseases.

In addition to BioMIL- $4,{ }^{128}$ a number of other promising $\mathrm{Ca}(\mathrm{II})$ bisphosphonate CPs have been discovered. The nitrogencontaining bisphosphonates pamidronate and zoledronate are cytotoxic against cancer cells but have unfavourable pharmacokinetic properties. These drugs have been successfully incorporated into nanoscale Ca CPs as ligands. ${ }^{149}$ The CPs were coated with single lipid bilayers to improve their stability in biologically relevant media. When combined with lipid coating, the nanoscale CPs proved highly effective against human lung and pancreatic cancer cells, with vastly superior performance over the free bisphosphonates. Ca CPs with $p$-xylylenebisphosphonate have been prepared with only water as solvent. ${ }^{144}$ The reported synthetic procedure involved autoclaving the reaction mixtures at $180{ }^{\circ} \mathrm{C}$ for 3 days but this can likely be substituted with an alternative method, especially where well-defined single crystals are not required. One of these Ca $p$-xylylenebisphosphonate CPs stimulated bone mineralization in experiments with MG63 osteoblast-like cells.

Magnesium. $\mathrm{Mg}$ is the $7^{\text {th }}$ most common element in the earth's crust, with significant quantities dissolved in seawater where it is the $5^{\text {th }}$ most abundant element (if $\mathrm{O}$ and $\mathrm{H}$ are discounted). ${ }^{125,126}$ It is a key element in the human diet with recommended daily allowances in the hundreds of milligram quantities and is required by plants where $\mathrm{Mg}^{2+}$ is at the centre of chlorophyll. As a component of CPs, $\mathrm{Mg}$ is less popular than other metals, such as various transition metals. However, it's abundance, biocompatibility and varied CP properties make further exploration worthwhile. A recent review specifically covers Mg-based CPs and their applications in gas sorption and separation, fluorescent sensing, energy applications and catalysis. ${ }^{150}$

Mg-MOF-74, with open metal sites and infinite hexagonal pores, has been extensively studied because of its potential gas sorption applications, with a dynamic (flowing gas) $\mathrm{CO}_{2}$ sorption capacity of $8.9 \% .{ }^{151}$ The adsorbed $\mathrm{CO}_{2}$ can be released at $80{ }^{\circ} \mathrm{C}$, which is relatively low compared with other competing systems. Isoreticular to Mg-MOF-74 is a $3 \mathrm{D}$ porous $\mathrm{CP}$ based on the anti-inflammatory drug olsalazine as ligand (a BioMOF according to the definition by McKinlay et $a l^{6}{ }^{6}$ ). Analogues with $\mathrm{Fe}, \mathrm{Co}, \mathrm{Ni}, \mathrm{Zn}$ were also prepared but the $\mathrm{Mg}$ version is of particular interest because of its excellent biocompatibility. Multicomponent drug release was demonstrated under simulated physiological conditions with olsalazine being the first drug and phenethylamine, a central nervous system stimulant chosen as model second drug, encapsulated as guest. ${ }^{152}$

$\mathrm{Mg}^{2+}$ has been combined with a carboxylate-phosphonate ligand in water and acetonitrile to prepare a 2D CP capable of $\mathrm{Fe}^{3+}$ luminescent sensing in aqueous medium. The pure $\mathrm{Mg}$ $\mathrm{CP}$ emits blue light in aqueous medium. This CP emission intensity is much greater than that of the free ligand. In the presence of various di- and trivalent metal ions in aqueous solutions, the emission was dampened and, in the case of $\mathrm{Fe}^{3+}$ at approximately $600 \mu \mathrm{M}$, the luminescence was fully quenched. ${ }^{153}$

A 1D Mg imidazolate CP has been prepared by solvent-free synthesis directly from the ligand melt. $\mathrm{Mg}$ metal and solid imidazole were combined in a sealed vessel and heated to $90{ }^{\circ} \mathrm{C}$ (ligand melting point) for $42 \mathrm{~h}$, yielding crystals of the CP upon cooling. ${ }^{154}$ A similar result was achieved for $\mathrm{Ca}$, resulting in a $2 \mathrm{D} \mathrm{Ca}$ imidazolate $\mathrm{CP}$, although for the $\mathrm{Ca} \mathrm{CP}$, higher temperature (as much as $145^{\circ} \mathrm{C}$ ) and much longer reaction time were required. ${ }^{154}$

A plethora of further CPs with $\mathrm{Mg}^{2+}$ and $\mathrm{Ca}^{2+}$ ion metal ion nodes have been reported. Consideration must be given to synthetic routes and the ligands selected, both with regards to source and end-of-life fate, but the significant number of syntheses conducted in water, in benign solvents, or in solvent-free conditions, and the increasing range of bio-based ligands reported indicates that these Group II metal ion CPs may provide a rich source of potentially green materials for a wide range of applications.

\section{d-Block}

A wide range of d-block metals are employed in CP synthesis, but many are contraindicated, particularly where the CP may be ingested by animals or humans. As with all metal complexes, solubility often defines toxicity.

Iron. $\mathrm{Fe}$ is relatively safe to humans and the environment. Liu et al. recently published a review covering various aspects of Fe-based MOFs with respect to environmental remediation applications. ${ }^{155}$

The Fe-MIL series has been extensively studied, particularly towards gas storage, drug delivery and catalysis applications. Some important compounds in the series are: MIL-88A with fumarate as linker; MIL-53, MIL-88B and MIL-101 with terephthalate as linker; and MIL-100 with 1,3,5-benzene tricarboxylate as linker. It has been noted that the Fe(III) fumarate $3 \mathrm{D}$ porous CP MIL-88A has the same chemical composition as the commercially available salt iron fumarate, which is approved for medical treatment. ${ }^{6}$ An in vitro toxicity study of MIL-100(Fe) found that this $\mathrm{CP}$ exhibited good biocompatibility and low cytotoxicity. The safe dosage level was determined to be $80 \mu \mathrm{g}$ $\mathrm{mL}^{-1} \cdot{ }^{156}$ Recently a range of bimetallic CPs based on MIL-100 $(\mathrm{Fe}, \mathrm{M})$ have been prepared by green synthesis in water at room temperature, using $\mathrm{Na}_{3} \mathrm{BTC}$, the sodium salt of trimesic acid, as ligand source. ${ }^{157}$

The related BioMIL series is a set of CPs that incorporate both a therapeutically active ligand and a metal ion that is benign or beneficial to human health. First in the series is an Fe(III)-based CP called BioMIL-1 (Fig. 15), which incorporates vitamin B3 (also known as niacin of nicotinic acid) as ligand and was reported as the first therapeutically active MOF. ${ }^{130}$ Biological delivery of the active component is based on degradation of the MOF. The vitamin B3 release rate was estimated under simulated physiological conditions. Elsewhere, other vitamin B3 porous CPs were investigated as carriers for the delivery of therapeutic NO. ${ }^{158}$ However, these later versions 


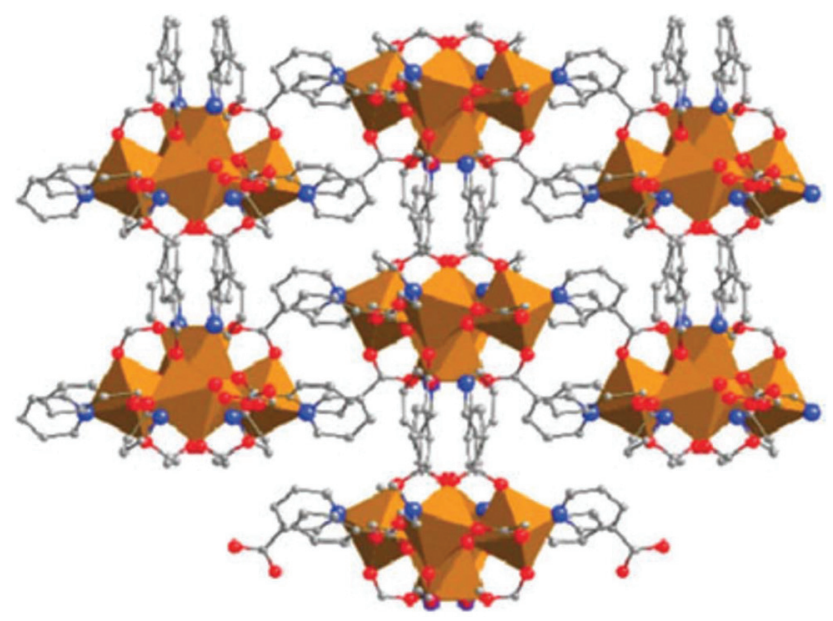

Fig. 15 Projection along [001] for the single-crystal X-ray structure of BioMIL-1, based on Fe(III) and vitamin B3. Iron octahedra, and O, C and N atoms are represented in orange, red, grey and blue, respectively. $\mathrm{H}$ atoms are omitted for clarity. Reprinted from ref. 130 with permission from the Royal Society of Chemistry.

were based on $\mathrm{Ni}$ (II) and $\mathrm{Co}(\mathrm{II})$, which are far less attractive than $\mathrm{Fe}(\mathrm{III})$ in the context of biomedical applications.

$\mathrm{Fe}(\mathrm{III})$ readily forms metal-organic gels with a variety of carboxylate-based ligands. Fe(III) forms CP gels with 1,3,5-benzenetricarboxylic (BTC) via conventional solvothermal synthesis and by green synthetic routes. Fe(III) BTC gels were reported as aerogels based on a precursor CP gel prepared by mixing ethanolic solutions of the $\mathrm{Fe}\left(\mathrm{NO}_{3}\right)_{3}$ and the ligand. Unreacted reagents were removed by Soxhlet extraction and the molecular formula, $\left[\mathrm{Fe}_{3} \mathrm{O}\left(\mathrm{C}_{6} \mathrm{H}_{3}(\mathrm{COO})_{3}\right)_{2} \mathrm{NO}_{3}\right]_{n}$, determined by elemental analysis. ${ }^{159}$ In a separate study $\mathrm{Fe}(\mathrm{III}) \mathrm{BTC}$ gels were prepared from $\mathrm{Fe}\left(\mathrm{NO}_{3}\right)_{3}$ as well as from $\mathrm{FeCl}_{3}$. The $\mathrm{FeCl}_{3}$-derived material gelled at a slower rate. ${ }^{160}$ The CP gels were evacuated under various conditions and one of the resultant aerogels exhibited $\mathrm{CO}_{2}$ sorption capacities of $5.9 \mathrm{wt} \%$ at 1.1 bar and $33 \mathrm{wt} \%$ at 30 bar. Fe(III) BTC gels have been investigated for sorption of $\mathrm{As}^{5+}$ ions from aqueous solution (Fig. 16) with vastly superior sorption capacity over commercially available iron oxide powders, although the CP gel was prepared by an unsatisfactory method using DMF at $150{ }^{\circ} \mathrm{C}$ for $24 \mathrm{~h} .{ }^{161}$ The $\mathrm{CP}$ gel absorbed $12.3 \mathrm{mg} \mathrm{g}^{-1}$ of $\mathrm{As}^{5+}$ as compared with
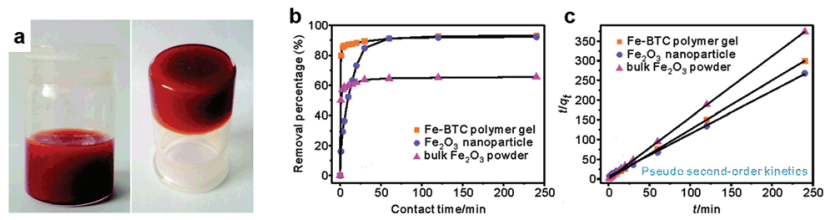

Fig. 16 (a) Fe(III) BTC (1,3,5-benzenetricarboxylic) CP gel. (b) Percentage of As(v) adsorption with increasing contact time. (c) Pseudosecond-order kinetic plots for $\mathrm{As}(\mathrm{v})$ adsorption. Adsorption plots are given for the $\mathrm{Fe}\left({ }_{11}\right) \mathrm{BTC}$ CP gel, $\mathrm{Fe}_{2} \mathrm{O}_{3}$ nanoparticles and bulky $\mathrm{Fe}_{2} \mathrm{O}_{3}$ powder at $\mathrm{pH} 4,5.0 \mathrm{~g} \mathrm{~L}^{-1}, 298 \mathrm{~K}$. Reprinted with permission from ref. 161. Copyright 2012 American Chemical Society.
$6.4 \mathrm{mg} \mathrm{g}^{-1}$ for $\mathrm{Fe}_{2} \mathrm{O}_{3}$ nanoparticles and $1.1 \mathrm{mg} \mathrm{g}^{-1}$ for bulky $\mathrm{Fe}_{2} \mathrm{O}_{3}$ powders. Similarly $\mathrm{Fe}(\mathrm{III})$ and 1,4-napthalenedicarboxylic acid form a CP gel with a far superior $\mathrm{As}^{5+}$ sorption capacity of $144 \mathrm{mg} \mathrm{g}^{-1} \cdot{ }^{162}$

Marquez et al. prepared the MOF $\mathrm{Fe}_{3}(\mathrm{BTC})_{2}$, which is commercially available as Basolite F300 (a fine chemical produced by BASF), by a green and scalable aerosol route called "evaporation induced self-assembly". The group obtained their best results using low concentrations of cetyltrimethyl ammonium bromide as a templating agent. ${ }^{131}$

Zinc. $\mathrm{Zn}$ is considered to be relatively non-toxic, is an important biological trace element in humans, and is one of the most prolific metal centres in CP chemistry. While $\mathrm{Zn}$ is moderately abundant in the earth's crust, it is heavily mined and there is some concern about resource depletion. ${ }^{125}$ The archetypal 3D porous $\mathrm{CP}$ and one that ushered in the modern field of MOF research, MOF-5 was originally reported with $\mathrm{Zn}$ (II) as metal centre. ${ }^{163}$ Many examples of other Zn(II)-based CPs have already been described here in the sections covering favourable ligands.

The so-called Zn(II) "paddle-wheel" secondary building unit has been extensively exploited in the preparation of mixedligand MOFs, such as those based on carboxylate- and pyridylbearing ligands. ${ }^{164}$

BioMIL-5 is a CP incorporating $\mathrm{Zn}$ (II) and azelaic acid that was originally prepared by hydrothermal synthesis. The antimicrobial activity of BioMIL-5 has been demonstrated against Staphilococcus bacteria. ${ }^{165}$

Zn(II) CP hydrogels and flower-like microparticles (Fig. 17) were synthesised by combining $\mathrm{Zn}\left(\mathrm{NO}_{3}\right)_{2}$ with guanine and cytosine as ligands. The hydrogels, based on nanofibre particles, were obtained from single-ligand reactions with pure guanine or cytosine and the flower-like microparticles were

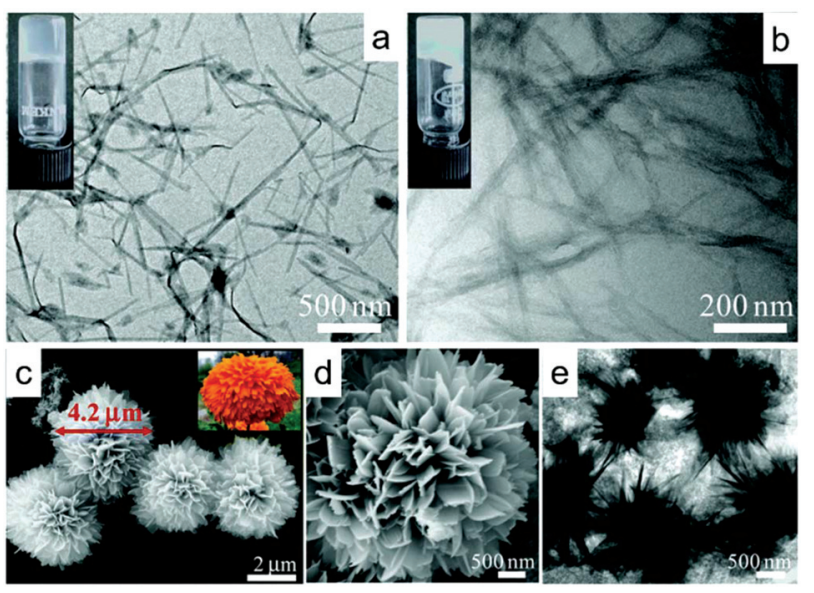

Fig. 17 TEM images of hydrogels: (a) Zn(॥) cytosine CP and (b) Zn(॥) guanine CP. Flower-like microparticles of $\mathrm{Zn}(\mathrm{II})$ cystine/guanine microparticles: (c) SEM image with inset of a marigold flower, (d) magnified SEM image, (e) TEM image. Reprinted from ref. 134 with permission from the Royal Society of Chemistry. 
obtained from mixed ligand reactions that combined guanine with cytosine. The materials were effective towards photocatalytic degradation of methylene blue and methyl orange, with the single-ligand hydrogels outperforming the mixedligand microparticles in terms of catalytic activity. ${ }^{134}$

A variety of $\mathrm{Zn}$ dicarboxylates are well-known heterogeneous catalysts for copolymerisation of epoxides with $\mathrm{CO}_{2}$. These include CPs based on succinic, adipic, glutaric and pimelic acid. $^{133}$

Titanium. Ti is earth abundant and is considered to be of low toxicity but research on $\mathrm{Ti}(\mathrm{Iv})$ CPs remains underdeveloped when compared with several other transition metals. ${ }^{166,167}$ The first reported Ti(Iv) MOF is MIL-91, which incorporates a phosphonate ligand and was discovered along with its $\mathrm{Al}$ (III) analogue. ${ }^{168}$ More recently a scalable green synthesis for MIL-91, in refluxing aqueous medium, has been reported. ${ }^{169}$ Previous synthetic routes had required $\mathrm{HF}$ or hydrothermal reaction conditions. MIL-125 is another important Ti(Iv) 3D CP incorporating terephthalic acid as organic linker. ${ }^{170}$ The original MIL-125 and its aminoterepthalate analogue MIL-125- $\mathrm{NH}_{2}$ have been explored for applications such as $\mathrm{H}_{2}$ sorption, ${ }^{171}$ photocatalytic reduction of $\mathrm{CO}_{2}$ to $\mathrm{CH}_{4}{ }^{172}$ and photocatalytic chemical fixation of $\mathrm{CO}_{2} \cdot{ }^{173}$

A systematic approach, based on Ti(Iv) isopropoxide clusters $\left[\left(\mathrm{Ti}_{3} \mathrm{O}\right)(\mathrm{iPrO})_{8}\right]^{2+}$ and $\left[\left(\mathrm{Ti}_{4} \mathrm{O}_{2}\right)(\mathrm{iPrO})_{6}\right]^{6+}$ and various carboxylate linkers, was employed to prepare a range of Ti(Iv) CPs, including $1 \mathrm{D}$ and $2 \mathrm{D}$ structures and a rare structure referred to as a "2D $\rightarrow$ 3D polycatenation framework". ${ }^{174}$ Copper iodide dopants were incorporated to impart photoluminescence properties.

A 3D porous Ti(Iv) CP, MIP-177-LT with 3,3',5,5'tetracarboxydiphenylmethane as ligand was prepared under mild reflux of the reagents, without the need for any added solvents. Upon calcining, MIP-177-LT underwent an irreversible phase transformation to the high temperature phase MIP-177$\mathrm{HT}$, which comprises ultrathin $\mathrm{Ti}-\mathrm{O}$ nanowires connected via the organic ligand. ${ }^{175}$ Later, exceptional proton conductivity of $2.6 \times 10^{-2} \mathrm{~S} \mathrm{~cm}^{-1}$ at $298 \mathrm{~K}$ and $95 \% \mathrm{RH}$ was demonstrated for a related compound, MIP-177- $\mathrm{SO}_{4} \mathrm{H}-\mathrm{LT}$, where an $\mathrm{HSO}_{4}{ }^{-}$ion is coordinated to the metal node as an additional component. Coordinated $\mathrm{HSO}_{4}{ }^{-}$is introduced post-synthetically, via treatment of MIP-177-LT with $\mathrm{H}_{2} \mathrm{SO}_{4} \cdot{ }^{176}$

Green scalable synthesis has been reported for a Ti(Iv) MOF designated MIP-207. A strategy based on a $\mathrm{Ti}_{8} \mathrm{O}_{8}$ cluster precursor, combined with ligand exchange, was used to demonstrate rational design of a series of Ti(Iv) CPs, which is known to be challenging because of the complex chemistry of $\mathrm{Ti}$ in solution. $^{135}$

Zirconium. $\mathrm{Zr}$ is relatively abundant in the earth's crust but is not as easily accessible as other metals discussed here, such as Fe and Ti. UiO-66, based on $\mathrm{Zr}$ (Iv) and terephthalic acid, and its many analogues are highly researched because of excellent sorption and catalytic properties, and exceptional aqueous and thermal stability, with good hydrolytic stability even under acidic conditions. ${ }^{136}$ UiO-66- $\mathrm{NO}_{2}$ is remarkably stable across a broad $\mathrm{pH}$ range, including highly basic and highly acidic con- ditions. ${ }^{137}$ MOF-801 is a $\mathrm{Zr}(\mathrm{IV})$ fumarate CP capable of selective sorption of fluoride ions from brick tea. ${ }^{146} \mathrm{Zr}$ (Iv) CP gels based on UiO-66, MOF-801 and MOF-808 have been prepared by combining $\mathrm{ZrCl}_{4}$ with the respective ligands in solution at ambient temperature or $90{ }^{\circ} \mathrm{C}$. No acid or base reagents were added because lowering the $\mathrm{pH}$ was found to impede gelation, while raising the $\mathrm{pH}$ favoured particulate gel formation. The gel based on MOF-808, with 1,3,5-benzenetricarboxylic as ligand, was found to be exceptionally thermally and chemically stable, including in concentrated $\mathrm{HNO}_{3}{ }^{177}$

\section{p-Block}

Aluminium. Al is the most earth abundant metal and most important p-block metal ion for construction of green CPs. Férey and co-workers are credited for their extensive work on a variety of Al-based porous CPs, as part of their research on the MIL-series.

An Al(III) fumarate CP, known as MIL-53-FA and commercially available as Basolite A520, produced by BASF at ton scale. ${ }^{178}$ This MOF exhibits exceptional hydrothermal stability and is used in natural gas storage applications. Scalable production of MIL-53-FA has been achieved at a space time yield of $97159 \mathrm{~kg} \mathrm{~m}^{-3}$ day $^{-1}$ and a rate of $5.6 \mathrm{~kg} \mathrm{~h}^{-1} .{ }^{179}$ Nanoflakes of MIL-53-FA have been synthesised by combining sodium aluminate with fumaric acid in water at $90^{\circ} \mathrm{C}$ with the resultant material showing relatively good volatile organic solvent sorption capacity and selective sorption of dichloromethane over trichloromethane. ${ }^{180}$

In the section covering ligand selection we highlighted MIL-160, well-known $\mathrm{Al}(\mathrm{III}) \mathrm{CP}$ that has been explored as a water sorbent for heat exchange applications. ${ }^{78}$

An extensive series of $\mathrm{Al}(\mathrm{III}) \mathrm{CPs}$, with aliphatic dicarboxylic acids as ligands, has been prepared by Mani and co-workers. These CPs were tested for efficiency towards enhancing nucleation of isotactic polypropylene (iPP), which is important for controlling iPP crystallisation during polymer processing. Favourable results were obtained, particularly for the $\mathrm{Al}(\mathrm{III})$ succinate $\mathrm{CP} .^{181}$

\section{f-Block}

Despite lanthanide compounds being explored as therapeutic agents ${ }^{182}$ lanthanides have moderate to high toxicity, depending on their chemical form, while the actinides are generally toxic to humans. ${ }^{183}$ Additionally, the lanthanides and actinides are not earth abundant (the lanthanides, along with Sc and Y, are classified as rare-earth elements) and pose environmental hazards, making them unfavourable as metal centres for green CPs. Among others, pulmonary, ${ }^{184,185}$ liver $^{186}$ and blood-related toxicity have been investigated. In a study of their effect on hemoglobin, lanthanide and actinide ions disrupted the alpha-helix conformation at lower concentrations, while above $75 \mu \mathrm{M}$, interaction with heme interfered with oxygen binding. ${ }^{187}$ 


\section{Solvents used in synthesis}

Among the most common solvents employed in CP synthesis are hazardous solvents such as $N, N^{\prime}$-dimethylformamide (DMF) and $N, N^{\prime}$-dimethylacetamide (DMAc), which are both toxic by inhalation (H332) and via skin contact (H312) and may be harmful to unborn children (H360D), and methanol, which is also toxic by inhalation (H331) and dermal exposure (H311). As Reinsch has argued, ${ }^{28}$ the ideal solvent for CP synthesis is water, followed by ethanol and acetic acid (both obtainable from renewable feedstocks). Recyclable organic solvents, that are stable under the reaction conditions, are to be considered as a last resort.

There are examples of MOFs where the original synthesis under harsh conditions has been replaced with a reaction in more sustainable solvent medium. ZIF-8 is an example where organic solvents were originally employed, but efficient synthesis can now be achieved in water. ZIF-8 was originally synthesised by dissolving 2-methylimidazole in methanol and layering onto a solution of $\mathrm{Zn}(\mathrm{OH})_{2}$ in $25 \%$ aqueous ammonia to yield crystals after one month. ${ }^{188}$ The procedure was improved upon to obtain the product after $24 \mathrm{~h}$ by combining $\mathrm{Zn}\left(\mathrm{NO}_{3}\right)_{2} \cdot 4 \mathrm{H}_{2} \mathrm{O}$ with 2-methylimidazole in $\mathrm{DMF}$ at $140{ }^{\circ} \mathrm{C}$ for 24 h. ${ }^{189}$ In contrast to the harsh conditions of solvothermal synthesis, a straightforward green synthesis produced ZIF-8 as nanocrystals within several minutes by combining $\mathrm{Zn}$ $\left(\mathrm{NO}_{3}\right)_{2} \cdot 6 \mathrm{H}_{2} \mathrm{O}$ and 2-methylimidazole in water at room temperature, although a large excess of ligand was required. ${ }^{190}$ In many cases the original synthetic routes and methods were chosen for the preparation of large crystalline particles amenable to analysis by single crystal X-ray diffractometry, but more readily scaled methods using benign solvents and lower (frequently even ambient) temperatures are possible. In addition, a move away from hydro- or solvothermal methods mitigates the requirement for high pressure apparatus.

\section{Low solvent and solvent-free methods}

Mechanochemistry is a synthetic approach involving intimate mixing of reagents by techniques such as ball-milling, grinding or extrusion. Its primary advantage over conventional synthetic methods is the minimisation or elimination of (typically hazardous) organic solvents.

Friščić and co-workers have developed several low-solvent and solvent-free approaches to the synthesis of metal-organic frameworks based on grinding and milling. ${ }^{30} \mathrm{CP}$ synthesis by ball-milling has been investigated by in situ X-ray powder diffraction using synchrotron radiation, shedding light on mechanistic aspects of these reactions. ${ }^{191-193}$ In situ monitoring of the mechanochemical synthesis of HKUST-1 revealed that the reaction proceeds either directly (without a discernible intermediate phase) or via one of two previously unidentified CP intermediates. A crystal structure could be determined for one of these intermediates, which is a mononuclear CP. ${ }^{191}$ By a similar analytical method it was discovered that the synthesis of MOF-74 from ZnO, an excellent 'green' metal source, and 2,5-dihydroxyterephthalic acid by milling in the presence of water, proceeds via a non-porous intermediate $\mathrm{CP}^{192}$ The Friščić group has also been able to demonstrate successful synthesis of several close-packed ZIFs (zinc imidazolate frameworks) by exposing the reactants to high humidity at moderate temperatures of up to $45{ }^{\circ} \mathrm{C}$ in the presence of a salt catalyst; a process referred to as "accelerated ageing" (Fig. 18). ${ }^{194}$ One of the close-packed ZIFs could be converted to the well-known ZIF-8 by exposure to methanol vapour. The accelerated aging approach was improved to achieve multi-gram synthesis of ZIF-8, its Co(II) analogue ZIF-67 and a related ZIF based on Zn and 2-ethylimidazole, ${ }^{195}$ and extended to the synthesis of other 2D and 3D CPs based on $\mathrm{Zn}$ (II), Ni(II) and $\mathrm{Co}(\mathrm{II}) .{ }^{196}$ Recently accelerated aging has been referred to as a 'geomimetic' approach, inspired by geology and mimicking the natural process of mineral formation. ${ }^{197}$

Efficient continuous production of MOFs by extrusion, with little to no solvent, was first achieved by James and co-workers using single- and twin-screw extruders, demonstrating the method on archetypal MOFs including HKUST-1 and ZIF-8. For ZIF-8 the synthesis was achieved completely free of additional solvent by extruding at elevated temperature (melt phase synthesis). ${ }^{198}$

Mechanochemistry methods have frequently been investigated for the synthesis of UiO-66, based on terephthalic acid as linker, alongside its analogue UiO-66- $\mathrm{NH}_{2}$, based on 2-aminoterephthalic acid as linker. An effective procedure for UiO-66- $\mathrm{NH}_{2}$ and UiO-66 was first reported by Užarević et al., who used a $\mathrm{Zr}(\mathrm{Iv})$ methacrylate cluster, $\mathrm{Zr}_{6} \mathrm{O}_{4}(\mathrm{OH})_{4}\left(\mathrm{C}_{2} \mathrm{H}_{3} \mathrm{CO}_{2}\right)_{12}$, as preorganised metal source, although small proportions of methanol were required. ${ }^{199}$ Scalable mechanochemical synthesis, by twin-screw extrusion, of UiO- $\mathrm{NH}_{2}$ in the presence of only water, eliminating organic solvents, was demonstrated by Karadeniz and co-workers. The method is based on the acetate cluster, $\left[\mathrm{Zr}_{6} \mathrm{O}_{4}(\mathrm{OH})_{4}\left(\mathrm{CH}_{3} \mathrm{COO}\right)_{12}\right]_{2}$, as precursor, prepared in a preliminary step from zirconium propoxide and acetic acid. In the same study UiO-66 synthesis was achieved by smaller scale milling only and triethylamine was required in addition to water. The greater solubility of 2-aminoterephthalic acid over terephthalic acid is a critical factor. ${ }^{200}$ A truly green procedure for the preparation of UiO-66 remains elusive.

The landmark 3D porous CP, MOF-5 has been targeted for green synthesis using alternative solvents. However, as yet no

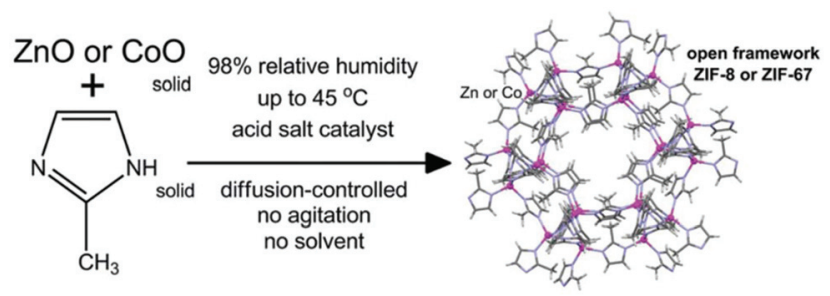

Fig. 18 Reaction scheme for the synthesis of ZIFs by the "accelerated aging" approach. Reprinted from ref. 194 with permission from the Royal Society of Chemistry. 
procedure has been reported that is completely free of hazardous organic solvents and yields MOF-5 of excellent crystallinity. Perhaps the best green method reported is a mechanochemical procedure where an oxozinc carboxylate complex ${ }^{201}$ is milled for 60 min with terephthalic acid. ${ }^{202}$ While MOF-5 could be prepare by solvent-free milling, the product was of poor crystallinity. Improved crystallinity was achieved by milling in the presence of THF and washing with THF. Thus, although cleaner methods have been developed for MOF-5, this example illustrates the challenge posed in achieving entirely green synthetic procedures for certain architectures.

Some examples of solvent-free melt phase synthesis have been reported. ${ }^{154,203}$ In general, a mixture of the solid ligand and metal is heated, in a sealed vial, to the ligand melting point and held at this temperature for an extended period of time before slow cooling. These procedures require long reaction times of several days and the metal is introduced in its elemental form, which would be extremely dangerous at scale. Melt phase extrusion, such as the earlier example of ZIF-8 synthesis, ${ }^{198}$ is likely to be more feasible.

\section{Ionic liquids and deep eutectic solvents (ionothermal synthesis)}

Ionic liquids (ILs) comprise ionic species in the liquid state. Examples of common IL ions are shown in Fig. 19. They are sometimes defined as salts with melting points below $100{ }^{\circ} \mathrm{C}$, although this is a somewhat arbitrary definition. Deep eutectic solvents (DESs) are a special class of ILs. DESs are eutectic mixtures of Lewis or Brønsted acids and bases, which can contain a variety of anionic and/or cationic species. ILs and DESs have received attention for their potential as sustainable alternative solvents. They are attractive as green solvents particularly because of their low vapour pressures. This translates to reactions that can be carried out at elevated temperature without generating the autogenous pressure that is usually associated with typical solvothermal reactions used in CP synthesis. They can also play a structure-directing role, which has been exploited in MOF synthesis. ${ }^{204}$
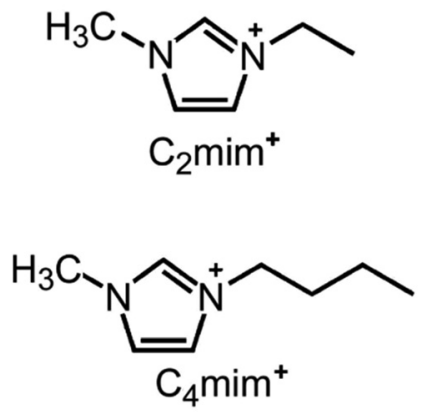

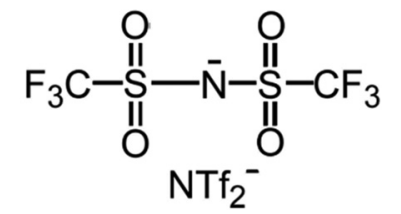

Fig. 19 Molecular structures of common ions in ionothermal synthesis: 1,3-dialkylimidazolium cations $\left[\mathrm{C}_{2} \mathrm{mim}\right]^{+}$and $\left[\mathrm{C}_{4} \mathrm{mim}\right]^{+}$, and the anions $\mathrm{OTf}^{-}$and $\mathrm{NTf}_{2}{ }^{-}$. Reprinted from ref. 204 with permission from the IUCr.
A variety of ZIFs have been synthesised using ionothermal synthesis. One of the earliest examples is the synthesis of two previously reported ZIFs along with two novel ZIFs using the IL 1-ethyl-3-methylimidazolium bis[(trifluoro-methyl)sulfonyl] imide as solvent. ${ }^{205} \mathrm{~A}$ related early example is the synthesis of the first $\mathrm{Zn}$ (II)-B(III)-imidazolate porous $\mathrm{CP}$, using the DES choline chloride/ $N, N^{\prime}$-dimethylurea (m-urea). ${ }^{206}$ Rapid synthesis of ZIFs has been achieved using microwave-assisted ionothermal synthesis. ZIF-8 was synthesised in $60 \mathrm{~min}$ at $140{ }^{\circ} \mathrm{C}$ using microwave-assisted ionothermal synthesis with 1-butyl-3-methyl-imidazolium tetra-fluoroborate as solvent. ${ }^{207}$ In a very similar microwave procedure, also using 1-butyl-3methylimidazoliumtetrafluoroborate, ZIF-61 was prepared in $40 \mathrm{~min}$ at $140{ }^{\circ} \mathrm{C} .{ }^{208}$

Polyoxometalate MOFs have been successfully synthesised under harsh ionothermal conditions of $170{ }^{\circ} \mathrm{C}$ for 5 days. ${ }^{209}$ The replacement of hazardous organic solvents with ILs is in this case undermined by the long reaction time and high temperature.

Zottnick et al. were able to prepare La(III) tetracyanoborate CPs by ionothermal reaction where the ionic liquid, 1-ethyl-3methylimidazolium tetracyanoborate serves as both solvent and ligand source. ${ }^{210}$

UiO-66 was originally synthesised solvothermally in DMF at $120{ }^{\circ} \mathrm{C}$ for $24 \mathrm{~h} .{ }^{211}$ This highly stable CP has been successfully synthesised at room temperature in the ionic liquids 1-hexyl-, 1-octyl and 3-methylimidazolium chloride. Yields were excellent and the reaction time was reduced to as short as $30 \mathrm{~min}$, while in DMF at room temperature UiO-66 may only precipitate after $120 \mathrm{~h}^{212}$

Despite the promise of ionic liquids as green synthesis medium, in many cases the conditions for CP reactions tend to involve relatively high temperatures and long reaction times. Interesting benefits seems to be the possibility of templating structures that difficult to obtain otherwise, and the simultaneous role of ILs as solvent medium and ligand. Another benefit is the tunability of ILs. Different ILs with slightly different molecular structures can be tested to optimise desired CP structures. Furthermore, the probability of accessing MOFs bearing a net charge is improved because of the IL ions can play a counterbalancing role.

\section{Alternative techniques for green synthesis}

As discussed earlier, there have been major advances in the development of mechanochemistry for low solvent or solventfree synthesis of CPs. Additionally, approaches exploiting ultrasound and electrochemistry have been used as alternative techniques for green synthesis of CPs.

\section{Sonochemical synthesis}

Cintas and Luche provided a detailed perspective on the sonochemical approach as it relates to green chemistry. ${ }^{213}$ The 
potential advantages of this method include energy savings, increased reaction rates, and improved or alternative selectivity towards reduced waste. In practice, however, there have been limited gains in terms of more sustainable synthesis. Many reported sonochemical procedures for CP preparation still rely on unfavourable solvents.

Son et al. were the first to specifically employ sonochemical synthesis in MOF research, preparing MOF-5 by a scalable method. ${ }^{214}$ However, their method relied on 1-methyl-2-pyrrolidone as reaction solvent, which poses risks to human health and the environment. Under ultrasonic treatment the reaction mixture reached $129-164{ }^{\circ} \mathrm{C}$. Higher power and its associated higher temperature yielded a higher rate of precipitation of the crystalline product.

In aqueous medium, $\mathrm{Cu}(\mathrm{II})$ was combined with $4,4^{\prime}$ (hexafluoroisopropylidene)-bis(benzoic acid) to prepare submicron sized MOF crystals by sonochemical synthesis. To modulate crystal morphology from high aspect ratio (needlelike) to more isotropic crystallites, a small quantity of 2-propanol was added to the reaction mixture. ${ }^{215}$

The extensively researched Mg-MOF-74 has been prepared sonochemically in as little as one hour, although DMF was used as solvent and triethylamine was required for ligand deprotonation. ${ }^{216}$

Scalability has been demonstrated by the preparation of well over $100 \mathrm{~g}$ of ZIF-8 at a yield of $85 \%$ in a $1 \mathrm{~L}$ sonochemical reaction using DMF as solvent. ${ }^{217}$ While the solvent system is unfavourable, the prospect of sonochemical synthesis of CPs at larger scales is promising.

\section{Electrochemical synthesis}

Electrochemical synthesis of CPs is relatively underdeveloped compared with other methods. A number of proof-of-concept experiments have been based on the well-known material HKUST-1. Researchers at BASF first demonstrated electrochemical synthesis of 3D porous CPs by preparing HKUST-1 with $\mathrm{Cu}$ electrodes in a solution of 1,3,5-benzentricarboxylic acid in methanol at $12-19 \mathrm{~V}$ and $1.3 \mathrm{~A}$ for $150 \mathrm{~min}$ to produce crystals of $0.5-5 \mu \mathrm{m}$ in size. ${ }^{218}$ Densely-packed patterned CP layers have been grown on $\mathrm{Cu}$ surfaces by electrochemical synthesis of HKUST-1. ${ }^{219}$ MOF-5 has been synthesised electrochemically in an IL medium, although DMF was still used. The reaction yielded unusual flower-like crystallites of MOF-5. ${ }^{220}$ A number of other archetypal 3D CPs, including ZIF-8 and MIL-100(Al) have also been prepared by electrochemical synthesis, requiring relatively short reaction times under mild conditions. ${ }^{221}$

\section{Competing with alternative materials}

The advantages of CPs over alternative competing materials include diversity, tunability, high surface area (porous CPs) and periodicity. However, many CPs suffer from poor thermal or chemical stability, which hinders further development towards industrial applications. Several reviews have addressed the subject of thermal, chemical and mechanical stability of MOFs. ${ }^{222-225}$ Additionally, considerable efforts have been dedicated specifically to understanding and improving MOF stability in aqueous media. ${ }^{226-228}$

MOFs tend to be compared with zeolites and mesoporous silica as competing alternative materials. In heterogeneous catalysis zeolites are cost effective and tend to outperform both MOFs and mesoporous silica because of their superior thermal and chemical stability. ${ }^{229}$ Howarth et al. have argued and that MOFs can now be routinely designed for thermal and chemical stability but that "it is difficult to envisage MOF structures with stabilities that greatly exceed the thermal, mechanical and chemical stabilities of the most robust existing MOFs". ${ }^{22}$ Among the most robust MOFs are UiO-66 and its analogues ${ }^{136,137}$ and $\mathrm{Ni}_{3}(\mathrm{BTP})_{2} \cdot{ }^{230}$ Some features of MOFs, including their distinct pore size range, higher diffusivity and ability to act as "single-site catalysts", present potential advantages over zeolites, particularly for liquid phase synthesis of fine chemicals under mild conditions and asymmetric catalysis. $^{229}$

CPs are typically highly crystalline and brittle. To compete with alternative materials that may be structurally tougher, more flexible or more easily shaped, deposition or in situ synthesis on supports is a common strategy. Common applications for such hybrid CP materials include heterogeneous catalysis, ${ }^{231}$ functional textiles ${ }^{232,233}$ and chromatographic separations. $^{234}$ Polymer films have been used as supports for the preparation of mixed matrix membranes incorporating MOFs. ${ }^{235}$ As a sustainable support for CPs, cellulose-based substrates have also been extensively explored. ${ }^{236}$

Various additional challenges need to be overcome to improve the industrial uptake of CPs. With respect to CPs for electrochemical energy storage and conversion applications, stability under electrochemical storage conditions, cost efficiency and scalable synthesis are key challenges that have been identified. ${ }^{237}$ Among CP gels, an emerging sub-class CP materials, detailed characterisation is a challenge that may necessitate the development of innovative characterisation techniques. ${ }^{10}$

\section{Conclusion}

Progress in the development of green CP materials has accelerated in recent years. The emergence of new CPs incorporating bio-based ligands and earth abundant metal ions is very encouraging. Remarkable materials such as CD-MOFs and the BioMIL series demonstrate that entirely benign, sustainable CPs are possible. However, despite environmental, energy and other sustainability applications being the target for many new CP materials, most CP research demonstrates little consideration for the sustainability of the novel materials themselves. There is great scope and a strong societal imperative for more extensive, direct research into CPs based on sustainable components and green synthetic procedures. 
Researchers investigating CP materials should be more intentional about their selection of reagents and their approach to synthesis, particularly where large-scale applications of bulk materials are envisioned. While elaborate ligands can be designed to impart specific properties, scalability will prove challenging if these are challenging to synthesise. As we have shown, a number of naturally-occurring and biobased ligands, some of which are already available as commodity chemicals, hold promise as useful ligands for green CPs. Selecting these increases the chances of good scalability of the final material. Every effort should be made to avoid harsh reaction conditions, involving hazardous organic solvents, which have been common in CP research. Sonochemical and electrochemical synthesis present some specific advantages over conventional solvothermal methods. However; the replacement of hazardous organic solvents with green alternatives or switching to solvent-free or low-solvent synthesis by continuous processing techniques like twin-screw extrusion is arguably a far more promising strategy for efficient scalable green synthesis.

It will not be sufficient to focus solely on improving the sustainability of CP materials. Cost is another important factor. One strategy has been to concentrate on bio-based ligands that are becoming increasingly important as commodity chemicals, such as lactic acid and 2,5-furandicarboxylic acid, because such chemicals are likely to become more affordable as demand increases and production efficiencies improve.

Furthermore, it will be important to demonstrate that sustainable CPs can at least match or, better yet, outperform existing alternative materials. This is a major challenge. Thousands of CPs have been discovered but many have proven to be appealing only as curiosities. While some have broken through to industrial testing, particularly in gas storage, textiles and catalysis, ${ }^{238,239}$ CPs have arguably not yet lived up to their promise as novel materials for the numerous potential applications envisioned.

It is worthwhile for researchers to revisit known CPs that fulfil the requirements of green chemistry but have not yet been thoroughly investigated towards potential applications. There is already an enormous library of known CPs. For many of these, single crystal X-ray structures have already been determined and are readily available from the Cambridge Structural Database. Existing green CP materials should be explored for previously overlooked properties and potential new applications.

Generally, 1D and 2D CPs have been neglected compared to 3D CPs. Constructing inherently 3D porous CPs (MOFs) usually requires rigid synthetic organic ligands and is frequently challenging without resorting to templating agents and undesirable reaction conditions. Even the archetypal MOFs, such as MOF-5, HKUST-1, ZIF-8 and UiO-66, despite their favourable attributes, present limitations that have made scaled-up applications difficult. 1D and 2D CPs may be comparatively better suited to green synthesis and can be constructed using a wide variety of benign, sustainable metal ions and ligands.

\section{Conflicts of interest}

There are no conflicts to declare.

\section{References}

1 S. R. Batten, N. R. Champness, X.-M. Chen, J. GarciaMartinez, S. Kitagawa, L. Öhrström, M. O’Keeffe, M. Paik Suh and J. Reedijk, Pure Appl. Chem., 2013, 85, 1715-1724.

2 Y. Wang, D. Astruc and A. S. Abd-El-Aziz, Chem. Soc. Rev., 2019, 48, 558-636.

3 A. K. Cheetham, C. N. R. Rao and R. K. Feller, Chem. Commun., 2006, 4780-4795.

4 K. Biradha, A. Ramanan and J. J. Vittal, Cryst. Growth Des., 2009, 9, 8-9.

5 I. Imaz, M. Rubio-Martínez, J. An, I. Solé-Font, N. L. Rosi and D. Maspoch, Chem. Commun., 2011, 47, 7287-7302.

6 A. C. McKinlay, R. E. Morris, P. Horcajada, G. Férey, R. Gref, P. Couvreur and C. Serre, Angew. Chem., Int. Ed., 2010, 49, 6260-6266.

7 H. Cai, Y. L. Huang and D. Li, Coord. Chem. Rev., 2019, 378, 207-221.

8 C. Serre, F. Millange, S. Surblé and G. Férey, Angew. Chem., Int. Ed., 2004, 43, 6286-6289.

9 F. Millange, C. Serre, N. Guillou, G. Férey and R. I. Walton, Angew. Chem., Int. Ed., 2008, 47, 4100-4105.

10 P. Sutar and T. K. Maji, Chem. Commun., 2016, 52, 80558074.

11 J. Zhang, X. Feng and P. Liao, in Gel Chemistry: Interactions, Structures and Properties, ed. J. Zhang, Y. Hu and Y. Li, Springer Nature, Singapore, 2018, pp. 61-118.

12 J. Hou, A. F. Sapnik and T. D. Bennett, Chem. Sci., 2020, 11, 310-323.

13 P. T. Anastas and J. C. Warner, Green Chemistry: Theory and Practice, Oxford University Press, New York, 1998.

14 E. Loukopoulos and G. E. Kostakis, J. Coord. Chem., 2018, 71, 371-410.

15 J. Chen, K. Shen and Y. Li, ChemSusChem, 2017, 10, 31653187.

16 S. Mukherjee, A. Kumar and M. J. Zaworotko, in MetalOrganic Frameworks (MOFs) for Environmental Applications, Elsevier, 2019, pp. 5-61.

17 K. Sumida, D. L. Rogow, J. A. Mason, T. M. McDonald, E. D. Bloch, Z. R. Herm, T.-H. Bae and J. R. Long, Chem. Rev., 2012, 112, 724-781.

18 J. Duan, W. Jin and S. Kitagawa, Coord. Chem. Rev., 2017, 332, 48-74.

19 Y. Peng and W. Yang, Adv. Mater. Interfaces, 2020, 7, 1-30.

20 R. B. Lin, S. Xiang, H. Xing, W. Zhou and B. Chen, Coord. Chem. Rev., 2019, 378, 87-103.

21 Y. Zhang, X. Cheng, X. Jiang, J. J. Urban, C. H. Lau, S. Liu and L. Shao, Mater. Today, 2020, DOI: 10.1016/j. mattod.2020.02.002.

22 J. Deng, F. Wu, P. Yu and L. Mao, Appl. Mater. Today, 2018, 11, 338-351. 
23 J. Q. Liu, Z. D. Luo, Y. Pan, A. Kumar Singh, M. Trivedi and A. Kumar, Coord. Chem. Rev., 2020, 406, 213145.

24 J. H. Clark, Green Chem., 1999, 1, 1-8.

25 P. Anastas and N. Eghbali, Chem. Soc. Rev., 2010, 39, 301312.

26 R. A. Sheldon, Green Chem., 2017, 19, 18-43.

27 L. Rogers and K. F. Jensen, Green Chem., 2019, 21, 34813498.

28 H. Reinsch, Eur. J. Inorg. Chem., 2016, 2016, 4290-4299.

29 B. Zhang, J. Zhang and B. Han, Chem. - Asian J., 2016, 11, 2610-2619.

30 T. Friščić, I. Halasz, V. Štrukil, M. Eckert-Maksić and R. E. Dinnebier, Croat. Chem. Acta, 2012, 85, 367-378.

31 Z. Ajoyan, P. Marino and A. J. Howarth, CrystEngComm, 2018, 20, 5899-5912.

32 T. Rajkumar, D. Kukkar, K. H. Kim, J. R. Sohn and A. Deep, J. Ind. Eng. Chem., 2019, 72, 50-66.

33 H. Furukawa, K. E. Cordova, M. O'Keeffe and O. M. Yaghi, Science, 2013, 341, 1230444.

34 S. Horike, S. Shimomura and S. Kitagawa, Nat. Chem., 2009, 1, 695-704.

35 M. L. A. Jansen and W. M. van Gulik, Curr. Opin. Biotechnol., 2014, 30, 190-197.

36 J. Becker, A. Lange, J. Fabarius and C. Wittmann, Curr. Opin. Biotechnol., 2015, 36, 168-175.

37 E. Skoog, J. H. Shin, V. Saez-Jimenez, V. Mapelli and L. Olsson, Biotechnol. Adv., 2018, 36, 2248-2263.

38 Y. Deng, L. Ma and Y. Mao, Biochem. Eng. J., 2016, 105, 16-26.

39 J. Cunha da Cruz, A. Machado de Castro and E. F. Camporese Sérvulo, 3 Biotech, 2018, 8, 138.

40 M. M. Cajnko, U. Novak, M. Grilc and B. Likozar, Biotechnol. Biofuels, 2020, 13, 66.

41 K. Kobayashi, T. Hattori, Y. Honda and K. Kirimura, J. Ind. Microbiol. Biotechnol., 2014, 41, 749-756.

42 S. Sanchez, R. Rodríguez-Sanoja, A. Ramos and A. L. Demain, J. Antibiot., 2018, 71, 26-36.

43 T. Loftsson and D. Duchêne, Int. J. Pharm., 2007, 329, 111.

44 G. Beobide, O. Castillo, J. Cepeda, A. Luque, S. PérezYáñez, P. Román and J. Thomas-Gipson, Coord. Chem. Rev., 2013, 257, 2716-2736.

45 Q. Yu, S. Black and H. Wei, J. Chem. Eng. Data, 2009, 54, 2123-2125.

46 M. C. Bernini, G. E. Gomez, E. V. Brusau and G. E. Narda, Isr. J. Chem., 2018, 58, 1044-1061.

47 M. C. Bernini, N. Snejko, E. Gutierrez-Puebla, E. V. Brusau, G. E. Narda and M. Á. Monge, Inorg. Chem., 2011, 50, 5958-5968.

48 R. F. D'vries, I. Camps and J. Ellena, Cryst. Growth Des., 2015, 15, 3015-3023.

49 Y. X. Chi, T. S. Liu, J. Jin, G. N. Zhang and S. Y. Niu, J. Phys. Chem. Solids, 2013, 74, 1745-1750.

50 D. Ghoshal, A. Kumar Ghosh, G. Mostafa, J. Ribas and N. Ray Chaudhuri, Inorg. Chim. Acta, 2007, 360, 17711775 .
51 P. M. Forster, N. Stock and A. K. Cheetham, Angew. Chem., Int. Ed., 2005, 44, 7608-7611.

52 S. Demir, G. K. Kantar, Y. Topcu and Q. Li, Transition Met. Chem., 2012, 37, 257-263.

53 R. Sibille, T. Mazet, B. Malaman, Q. Wang, E. Didelot and M. François, Chem. Mater., 2015, 27, 133-140.

54 C. Livage, P. M. Forster, N. Guillou, M. M. Tafoya, A. K. Cheetham and G. Férey, Angew. Chem., Int. Ed., 2007, 46, 5877-5879.

55 P. J. Saines, P. Jain and A. K. Cheetham, Chem. Sci., 2011, 2, 1929-1939.

56 H. H. M. Yeung, W. Li, P. J. Saines, T. K. J. Köster, C. P. Grey and A. K. Cheetham, Angew. Chem., Int. Ed., 2013, 52, 5544-5547.

57 A. Michaelides, V. Kiritsis, S. Skoulika and A. Aubry, Angew. Chem., Int. Ed. Engl., 1993, 32, 1495-1497.

58 J. Wang, Z. Wei, F. Guo, C. Li, P. Zhu and W. Zhu, Dalton Trans., 2015, 44, 13809-13813.

59 Y. Q. Zheng, H. L. Zhu, X. X. Guo and J. Y. Liu, Solid State Sci., 2013, 18, 42-49.

60 Y. J. Kim and D. Y. Jung, Inorg. Chem., 2000, 39, 14701475.

61 Z. G. Sun, Y. P. Ren, L. S. Long, R. Bin Huang and L. S. Zheng, Inorg. Chem. Commun., 2002, 5, 629-632.

62 D. T. De Lill, N. S. Gunning and C. L. Cahill, Inorg. Chem., 2005, 44, 258-266.

63 D. T. De Lill, D. J. Bozzuto and C. L. Cahill, Dalton Trans., 2005, 2111-2115.

64 P. J. Saines, P. T. Barton, M. Jura, K. S. Knight and A. K. Cheetham, Mater. Horiz., 2014, 1, 332-337.

65 Z. Y. Li, B. Zhai, S. Z. Li, G. X. Cao, F. Q. Zhang, X. F. Zhang, F. L. Zhang and C. Zhang, Cryst. Growth Des., 2016, 16, 4574-4581.

66 Z. Y. Li, C. Zhang, B. Zhai, J. C. Han, M. C. Pei, J. J. Zhang, F. L. Zhang, S. Z. Li and G. X. Cao, CrystEngComm, 2017, 19, 2702-2708.

67 R. M. Nair, M. R. Sudarsanakumar, S. Suma and M. R. Prathapachandra Kurup, J. Mol. Struct., 2016, 1105, 316-321.

68 M. Rose, D. Weber, B. V. Lotsch, R. K. Kremer, R. Goddard and R. Palkovits, Microporous Mesoporous Mater., 2013, 181, 217-221.

69 J. Wang, D. Ma, W. Liao, S. Li, M. Huang, H. Liu, Y. Wang, R. Xie and J. Xu, CrystEngComm, 2017, 19, 52445250 .

70 D. Y. Ma, J. Xie, Z. Zhu, H. Huang, Y. Chen, R. Su and H. Zhu, Inorg. Chem. Commun., 2017, 86, 128-132.

71 Y. Zhang and J. Wang, Inorg. Chim. Acta, 2018, 477, 8-14.

72 F. Bu, Q. Lin, Q. Zhai, L. Wang, T. Wu, S. T. Zheng, X. Bu and P. Feng, Angew. Chem., Int. Ed., 2012, 51, 8538-8541.

73 H. H. Li, Z. Niu, L. Chen, H. Bin Jiang, Y. P. Wang and P. Cheng, CrystEngComm, 2015, 17, 5101-5109.

74 Q. G. Zhai, X. Bu, X. Zhao, C. Mao, F. Bu, X. Chen and P. Feng, Cryst. Growth Des., 2016, 16, 1261-1267.

75 H. Wang, R. M. Wen and T. L. Hu, Eur. J. Inorg. Chem., 2014, 1185-1191. 
76 D. Feng, K. Wang, Z. Wei, Y. P. Chen, C. M. Simon, R. K. Arvapally, R. L. Martin, M. Bosch, T. F. Liu, S. Fordham, D. Yuan, M. A. Omary, M. Haranczyk, B. Smit and H. C. Zhou, Nat. Commun., 2014, 5, 5723.

77 H. Zhou, D. Feng and K. Wang, US Pat, 9724668B2, 2017.

78 A. Cadiau, J. S. Lee, D. Damasceno Borges, P. Fabry, T. Devic, M. T. Wharmby, C. Martineau, D. Foucher, F. Taulelle, C. H. Jun, Y. K. Hwang, N. Stock, M. F. De Lange, F. Kapteijn, J. Gascon, G. Maurin, J. S. Chang and C. Serre, Adv. Mater., 2015, 27, 4775-4780.

79 J. D. Einkauf, J. P. Karram, N. E. Greig, B. C. Chan and D. T. De Lill, Eur. J. Inorg. Chem., 2016, 1085-1092.

80 H. H. Li, W. Shi, N. Xu, Z. J. Zhang, Z. Niu, T. Han and P. Cheng, Cryst. Growth Des., 2012, 12, 2602-2612.

81 M. O. Barsukova, D. G. Samsonenko, A. A. Sapianik, S. A. Sapchenko and V. P. Fedin, Polyhedron, 2018, 144, 219-224.

82 M. Wahiduzzaman, D. Lenzen, G. Maurin, N. Stock and M. T. Wharmby, Eur. J. Inorg. Chem., 2018, 2018, 36263632.

83 A. Permyakova, O. Skrylnyk, E. Courbon, M. Affram, S. Wang, U. H. Lee, A. H. Valekar, F. Nouar, G. Mouchaham, T. Devic, G. De Weireld, J. S. Chang, N. Steunou, M. Frère and C. Serre, ChemSusChem, 2017, 10, 1419-1426.

84 N. Scales, Y. Zhang, M. Bhadbhade, I. Karatchevtseva, L. Kong, G. R. Lumpkin and F. Li, Polyhedron, 2015, 102, 130-136.

85 H. Wang, S. J. Liu, D. Tian, J. M. Jia and T. L. Hu, Cryst. Growth Des., 2012, 12, 3263-3270.

86 F. N. Shi, D. Ananias, T. H. Yang and J. Rocha, J. Solid State Chem., 2013, 204, 321-328.

87 M. Sadakiyo, T. Yamada and H. Kitagawa, J. Am. Chem. Soc., 2009, 131, 9906-9907.

88 M. Sadakiyo, T. Yamada and H. Kitagawa, J. Am. Chem. Soc., 2014, 136, 13166-13169.

89 I. Imaz, M. Rubio-Martínez, W. J. Saletra, D. B. Amabilino and D. Maspoch, J. Am. Chem. Soc., 2009, 131, 1822218223.

90 F. Pu, X. Liu, B. Xu, J. Ren and X. Qu, Chem. - Eur. J., 2012, 18, 4322-4328.

91 H. Wu, C. Tian, Y. Zhang, C. Yang, S. Zhang and Z. Jiang, Chem. Commun., 2015, 51, 6329-6332.

92 J. S. Shen, G. J. Mao, Y. H. Zhou, Y. B. Jiang and H. W. Zhang, Dalton Trans., 2010, 39, 7054-7058.

93 E. Chen, B. Guo, B. Zhang, L. H. Gan and J. R. Gong, J. Nanosci. Nanotechnol., 2011, 11, 7682-7686.

94 C. Li, K. Deng, Z. Tang and L. Jiang, J. Am. Chem. Soc., 2010, 132, 8202-8209.

95 K. Liu, C. Yuan, Q. Zou, Z. Xie and X. Yan, Angew. Chem., Int. Ed., 2017, 56, 7876-7880.

96 S. Zechel, M. Hager, T. Priemel and M. Harrington, Biomimetics, 2019, 4, 20.

97 N. C. Kasuga, Y. Takagi, S. I. Tsuruta, W. Kuwana, R. Yoshikawa and K. Nomiya, Inorg. Chim. Acta, 2011, 368, 44-48.
98 K. Nomiya, S. Takahashi, R. Noguchi, S. Nemoto, T. Takayama and M. Oda, Inorg. Chem., 2000, 39, 33013311.

99 J.-H. Zhang, R.-Y. Nong, S.-M. Xie, B.-J. Wang, P. Ai and L.-M. Yuan, Electrophoresis, 2017, 38, 2513-2520.

100 J. Navarro-Sánchez, A. I. Argente-García, Y. MolinerMartínez, D. Roca-Sanjuán, D. Antypov, P. Campíns-Falcó, M. J. Rosseinsky and C. Martí-Gastaldo, J. Am. Chem. Soc., 2017, 139, 4294-4297.

101 C. Martí-Gastaldo, J. E. Warren, M. E. Briggs, J. A. Armstrong, K. M. Thomas and M. J. Rosseinsky, Chem. - Eur. J., 2015, 21, 16027-16034.

102 E. V. Anokhina and A. J. Jacobson, J. Am. Chem. Soc., 2004, 126, 3044-3045.

103 E. V. Anokhina, Y. B. Go, Y. Lee, T. Vogt and A. J. Jacobson, J. Am. Chem. Soc., 2006, 128, 9957-9962.

104 L. Antolini, L. Menabue, G. C. Pellacani and G. Marcotrigiano, J. Chem. Soc., Dalton Trans., 1982, 25412543.

105 H. Schmidbaur, I. Bach, J. Riede, G. Müller, J. Helbig and G. Hopf, Chem. Ber., 1988, 121, 795-797.

106 Y. Zhang, M. K. Saha and I. Bernal, CrystEngComm, 2003, 5, 34-37.

107 M. Mizutani, N. Maejima, K. Jitsukawa, H. Masuda and H. Einaga, Inorg. Chim. Acta, 1998, 283, 105-110.

108 A. R. Hedges, Chem. Rev., 1998, 98, 2035-2044.

109 R. A. Smaldone, R. S. Forgan, H. Furukawa, J. J. Gassensmith, A. M. Z. Slawin, O. M. Yaghi and J. F. Stoddart, Angew. Chem., Int. Ed., 2010, 49, 8630-8634.

110 R. S. Forgan, R. A. Smaldone, J. J. Gassensmith, H. Furukawa, D. B. Cordes, Q. Li, C. E. Wilmer, Y. Y. Botros, R. Q. Snurr, A. M. Z. Slawin and J. F. Stoddart, J. Am. Chem. Soc., 2012, 134, 406-417.

111 J. J. Gassensmith, R. A. Smaldone, R. S. Forgan, C. E. Wilmer, D. B. Cordes, Y. Y. Botros, A. M. Z. Slawin, R. Q. Snurr and J. F. Stoddart, Org. Lett., 2012, 14, 14601463.

112 H. Lu, X. Yang, S. Li, Y. Zhang, J. Sha, C. Li and J. Sun, Inorg. Chem. Commun., 2015, 61, 48-52.

113 J. Sha, L. Wu, S. Li, X. Yang, Y. Zhang, Q. Zhang and P. Zhu, J. Mol. Struct., 2015, 1101, 14-20.

114 J. Q. Sha, X. H. Zhong, L. H. Wu, G. D. Liu and N. Sheng, RSC Adv. , 2016, 6, 82977-82983.

115 Z. Moussa, M. Hmadeh, M. G. Abiad, O. H. Dib and D. Patra, Food Chem., 2016, 212, 485-494.

116 L. Wang, X. Liang, Z. Chang, L. Ding, S. Zhang and B. Li, ACS Appl. Mater. Interfaces, 2018, 10, 42-46.

117 X. Li, T. Guo, L. Lachmanski, F. Manoli, M. MenendezMiranda, I. Manet, Z. Guo, L. Wu, J. Zhang and R. Gref, Int. J. Pharm., 2017, 531, 424-432.

118 J. Sha, X. Yang, L. Sun, X. Zhang, S. Li, J. Li and N. Sheng, Polyhedron, 2017, 127, 396-402.

119 V. Singh, T. Guo, H. Xu, L. Wu, J. Gu, C. Wu, R. Gref and J. Zhang, Chem. Commun., 2017, 53, 9246-9249.

120 J. M. Holcroft, K. J. Hartlieb, P. Z. Moghadam, J. G. Bell, G. Barin, D. P. Ferris, E. D. Bloch, M. M. Algaradah, 
M. S. Nassar, Y. Y. Botros, K. M. Thomas, J. R. Long, R. Q. Snurr and J. F. Stoddart, J. Am. Chem. Soc., 2015, 137, 5706-5719.

121 K. J. Hartlieb, J. M. Holcroft, P. Z. Moghadam, N. A. Vermeulen, M. M. Algaradah, M. S. Nassar, Y. Y. Botros, R. Q. Snurr and J. F. Stoddart, J. Am. Chem. Soc., 2016, 138, 2292-2301.

122 P. Chirik and R. Morris, Acc. Chem. Res., 2015, 48, 2495.

123 T. E. Graedel, E. M. Harper, N. T. Nassar, P. Nuss, B. K. Reck and B. L. Turner, Proc. Natl. Acad. Sci. U. S. A., 2015, 112, 4257-4262.

124 J. H. Duffus, Pure Appl. Chem., 2002, 74, 793-807.

125 R. M. Izatt, S. R. Izatt, R. L. Bruening, E. Izatt and B. A. Moyer, Chem. Soc. Rev., 2014, 43, 2451-2475.

126 J. R. Rumble, D. R. Lide and T. J. Bruno, CRC handbook of chemistry and physics : a ready-reference book of chemical and physical data, CRC Press, Boca Raton, 2019.

127 J. Yang, C. A. Trickett, S. B. Alahmadi, A. S. Alshammari and O. M. Yaghi, J. Am. Chem. Soc., 2017, 139, 8118-8121.

128 E. Alvarez, A. G. Marquez, T. Devic, N. Steunou, C. Serre, C. Bonhomme, C. Gervais, I. Izquierdo-Barba, M. ValletRegi, D. Laurencin, F. Mauri and P. Horcajada, CrystEngComm, 2013, 15, 9899-9905.

129 M. A. Matlinska, M. Ha, B. Hughton, A. O. Oliynyk, A. K. Iyer, G. M. Bernard, G. Lambkin, M. C. Lawrence, M. J. Katz, A. Mar and V. K. Michaelis, ACS Appl. Mater. Interfaces, 2019, 11, 32739-32745.

130 S. R. Miller, D. Heurtaux, T. Baati, P. Horcajada, J.-M. Grenèche and C. Serre, Chem. Commun., 2010, 46, 4526.

131 A. G. Marquez, P. Horcajada, D. Grosso, G. Ferey, C. Serre, C. Sanchez and C. Boissiere, Chem. Commun., 2013, 49, 3848-3850.

132 O. M. Yaghi, M. O'Keeffe, M. Eddaoudi and H. Li, Nature, 1999, 402, 276-279.

133 S. Klaus, M. W. Lehenmeier, E. Herdtweck, P. Deglmann, A. K. Ott and B. Rieger, J. Am. Chem. Soc., 2011, 133, 13151-13161.

134 B. Sharma, A. Mahata, S. Mandani, N. Thakur, B. Pathak and T. K. Sarma, New J. Chem., 2018, 42, 17983-17990.

135 S. Wang, H. Reinsch, N. Heymans, M. Wahiduzzaman, C. Martineau-Corcos, G. De Weireld, G. Maurin and C. Serre, Matter, 2020, 2, 440-450.

136 M. J. Katz, Z. J. Brown, Y. J. Colón, P. W. Siu, K. A. Scheidt, R. Q. Snurr, J. T. Hupp and O. K. Farha, Chem. Commun., 2013, 49, 9449-9451.

137 M. Kandiah, M. H. Nilsen, S. Usseglio, S. Jakobsen, U. Olsbye, M. Tilset, C. Larabi, E. A. Quadrelli, F. Bonino and K. P. Lillerud, Chem. Mater., 2010, 22, 6632-6640.

138 M. Mathew, S. Takagi and H. L. Ammon, J. Crystallogr. Spectrosc. Res., 1993, 23, 617-621.

139 M. Mathew and S. Takagi, Z. Kristallogr. - Cryst. Mater., 1995, 210, 199-201.

140 M. Mathew, S. Takagi, B. O. Fowler and M. Markovic, J. Chem. Crystallogr., 1994, 24, 437-440.
141 M. Mazaj, V. Kaucic, A. Golobic and N. Zabukovec Logar, Acta Crystallogr., Sect. C: Cryst. Struct. Commun., 2012, 68, 4-6.

142 R. L. Metcalf and A. R. Horowitz, in Ullmann's Encyclopedia of Industrial Chemistry, Wiley-VCH, Weinheim, 2014, DOI: 10.1002/14356007.s14_s01.

143 B. Slater, S. O. Wong, A. Duckworth, A. J. P. White, M. R. Hill and B. P. Ladewig, Chem. Commun., 2019, 55, 7319-7322.

144 F. N. Shi, J. C. Almeida, L. A. Helguero, M. H. V. Fernandes, J. C. Knowles and J. Rocha, Inorg. Chem., 2015, 54, 9929-9935.

145 L. Li, L. Guo, S. Pu, J. Wang, Q. Yang, Z. Zhang, Y. Yang, Q. Ren, S. Alnemrat and Z. Bao, Chem. Eng. J., 2019, 358, 446-455.

146 F. Ke, C. Peng, T. Zhang, M. Zhang, C. Zhou, H. Cai, J. Zhu and X. Wan, Sci. Rep., 2018, 8, 939.

147 S. R. Miller, P. Horcajada and C. Serre, CrystEngComm, 2011, 13, 1894-1898.

148 S. R. Miller, E. Alvarez, L. Fradcourt, T. Devic, S. Wuttke, P. S. Wheatley, N. Steunou, C. Bonhomme, C. Gervais, D. Laurencin, R. E. Morris, A. Vimont, M. Daturi, P. Horcajada and C. Serre, Chem. Commun., 2013, 49, 7773-7775.

149 D. Liu, S. A. Kramer, R. C. Huxford-Phillips, S. Wang, J. Della Rocca and W. Lin, Chem. Commun., 2012, 48, 2668-2670.

150 Z. F. Wu, B. Tan, W. P. Lustig, E. Velasco, H. Wang, X. Y. Huang and J. Li, Coord. Chem. Rev., 2019, 399, 213025.

151 D. Britt, H. Furukawa, B. Wang, T. G. Glover and O. M. Yaghi, Proc. Natl. Acad. Sci. U. S. A., 2009, 106, 20637-20640.

152 D. J. Levine, T. Runčevski, M. T. Kapelewski, B. K. Keitz, J. Oktawiec, D. A. Reed, J. A. Mason, H. Z. H. Jiang, K. A. Colwell, C. M. Legendre, S. A. Fitzgerald and J. R. Long, J. Am. Chem. Soc., 2016, 138, 10143-10150.

153 Y. Liu, J. Xu, X. Tang, Y. Ma, R. Yuan and R. Matsuda, Chem. Lett., 2019, 48, 156-158.

154 A. Zurawski, J. C. Rybak, L. V. Meyer, P. R. Matthes, V. Stepanenko, N. Dannenbauer, F. Würthner and K. Müller-Buschbaum, Dalton Trans., 2012, 41, 40674078.

155 X. Liu, Y. Zhou, J. Zhang, L. Tang, L. Luo and G. Zeng, ACS Appl. Mater. Interfaces, 2017, 9, 20255-20275.

156 G. Chen, X. Leng, J. Luo, L. You, C. Qu, X. Dong, H. Huang, X. Yin and J. Ni, Molecules, 2019, 24, 1211.

157 T. Steenhaut, S. Hermans and Y. Filinchuk, New J. Chem., 2020, 44, 3847-3855.

158 R. V. Pinto, F. Antunes, J. Pires, V. Graça, P. Brandão and M. L. Pinto, Acta Biomater., 2017, 51, 66-74.

159 M. R. Lohe, M. Rose and S. Kaskel, Chem. Commun., 2009, 6056-6058.

160 S. K. Nune, P. K. Thallapally and B. P. McGrail, J. Mater. Chem., 2010, 20, 7623-7625. 
161 B. J. Zhu, X. Y. Yu, Y. Jia, F. M. Peng, B. Sun, M. Y. Zhang, T. Luo, J. H. Liu and X. J. Huang, J. Phys. Chem. C, 2012, 116, 8601-8607.

162 J. Sui, L. Wang, W. Zhao and J. Hao, Chem. Commun., 2016, 52, 6993-6996.

163 H. Li, M. Eddaoudi, M. O’Keeffe and O. M. Yaghi, Nature, 1999, 402, 276-279.

164 B. Q. Ma, K. L. Mulfort and J. T. Hupp, Inorg. Chem., 2005, 44, 4912-4914.

165 C. Tamames-Tabar, E. Imbuluzqueta, N. Guillou, C. Serre, S. R. Miller, E. Elkaïm, P. Horcajada and M. J. BlancoPrieto, CrystEngComm, 2015, 17, 456-462.

166 H. Assi, G. Mouchaham, N. Steunou, T. Devic and C. Serre, Chem. Soc. Rev., 2017, 46, 3431-3452.

167 H. L. Nguyen, New J. Chem., 2017, 41, 14030-14043.

168 C. Serre, J. A. Groves, P. Lightfoot, A. M. Z. Slawin, P. A. Wright, N. Stock, T. Bein, M. Haouas, F. Taulelle and G. Férey, Chem. Mater., 2006, 18, 1451-1457.

169 V. Benoit, R. S. Pillai, A. Orsi, P. Normand, H. Jobic, F. Nouar, P. Billemont, E. Bloch, S. Bourrelly, T. Devic, P. A. Wright, G. De Weireld, C. Serre, G. Maurin and P. L. Llewellyn, J. Mater. Chem. A, 2016, 4, 1383-1389.

170 M. Dan-Hardi, C. Serre, T. Frot, L. Rozes, G. Maurin, C. Sanchez and G. Férey, J. Am. Chem. Soc., 2009, 131, 10857-10859.

171 C. Zlotea, D. Phanon, M. Mazaj, D. Heurtaux, V. Guillerm, C. Serre, P. Horcajada, T. Devic, E. Magnier, F. Cuevas, G. Férey, P. L. Llewellyn and M. Latroche, J. Chem. Soc., Dalton Trans., 2011, 40, 4879-4881.

172 J. Ding, M. Chen, X. Du, R. Shang, M. Xia, J. Hu and Q. Zhong, Catal. Lett., 2019, 149, 3287-3295.

173 S. Wu, X. Xing, D. Wang, J. Zhang, J. Chu, C. Yu, Z. Wei, M. Hu, X. Zhang and Z. Li, ACS Sustainable Chem. Eng., 2020, 8, 148-153.

174 C. Wang, C. Liu, H. R. Tian, L. J. Li and Z. M. Sun, Chem. - Eur. J., 2018, 24, 2952-2961.

175 S. Wang, T. Kitao, N. Guillou, M. Wahiduzzaman, C. Martineau-Corcos, F. Nouar, A. Tissot, L. Binet, N. Ramsahye, S. Devautour-Vinot, S. Kitagawa, S. Seki, Y. Tsutsui, V. Briois, N. Steunou, G. Maurin, T. Uemura and C. Serre, Nat. Commun., 2018, 9, 1-9.

176 M. Wahiduzzaman, S. Wang, J. Schnee, A. Vimont, V. Ortiz, P. G. Yot, R. Retoux, M. Daturi, J. S. Lee, J. S. Chang, C. Serre, G. Maurin and S. Devautour-Vinot, ACS Sustainable Chem. Eng., 2019, 7, 5776-5783.

177 J. Santos-Lorenzo, R. San José-Velado, J. Albo, G. Beobide, P. Castaño, O. Castillo, A. Luque and S. Pérez-Yáñez, Microporous Mesoporous Mater., 2019, 284, 128-132.

178 M. Gaab, N. Trukhan, S. Maurer, R. Gummaraju and U. Müller, Microporous Mesoporous Mater., 2012, 157, 131136.

179 M. Rubio-Martinez, T. D. Hadley, M. P. Batten, K. Constanti-Carey, T. Barton, D. Marley, A. Mönch, K. S. Lim and M. R. Hill, ChemSusChem, 2016, 9, 938-941.

180 L. Zhou, X. Zhang and Y. Chen, Mater. Lett., 2017, 197, 224-227.
181 M. R. Mani, R. Chellaswamy, Y. N. Marathe and V. K. Pillai, RSC Adv., 2016, 6, 1907-1912.

182 K. Wang, R. Li, Y. Cheng and B. Zhu, Coord. Chem. Rev., 1999, 190-192, 297-308.

183 R. S. Ripa, J. Kastrup, A. Ekblond, C. Stem, N. Medicine, T. H. Centre and C. Catheterization, in Encyclopedia of Metalloproteins, Springer, New York, 2013, pp. 1098-1103.

184 C. Lizon and P. Fritsch, Int. J. Radiat. Biol., 1999, 75, 1459-1471.

185 P. J. Haley, Health Phys., 1991, 61, 809-820.

186 H. I. Sarkander and W. P. Brade, Arch. Toxicol., 1976, 36, $1-17$.

187 A. Kumar, M. Ali, R. S. Ningthoujam, P. Gaikwad, M. Kumar, B. B. Nath and B. N. Pandey, J. Hazard. Mater., 2016, 307, 281-293.

188 X.-C. Huang, Y.-Y. Lin, J.-P. Zhang and X.-M. Chen, Angew. Chem., Int. Ed., 2006, 45, 1557-1559.

189 K. S. Park, Z. Ni, A. P. Cote, J. Y. Choi, R. Huang, F. J. Uribe-Romo, H. K. Chae, M. O'Keeffe and O. M. Yaghi, Proc. Natl. Acad. Sci. U. S. A., 2006, 103, 10186-10191.

190 Y. Pan, Y. Liu, G. Zeng, L. Zhao and Z. Lai, Chem. Commun., 2011, 47, 2071-2073.

191 T. Stolar, L. Batzdorf, S. Lukin, D. Žilić, C. Motillo, T. Friščić, F. Emmerling, I. Halasz and K. Užarević, Inorg. Chem., 2017, 56, 6599-6608.

192 P. A. Julien, K. Užarević, A. D. Katsenis, S. A. J. Kimber, T. Wang, O. K. Farha, Y. Zhang, J. Casaban, L. S. Germann, M. Etter, R. E. Dinnebier, S. L. James, I. Halasz and T. Friščić, J. Am. Chem. Soc., 2016, 138, 2929-2932.

193 L. S. Germann, A. D. Katsenis, I. Huskić, P. A. Julien, K. Užarević, M. Etter, O. K. Farha, T. Friščić and R. E. Dinnebier, Cryst. Growth Des., 2020, 20, 49-54.

194 M. J. Cliffe, C. Mottillo, R. S. Stein, D. K. Bučar and T. Friščić, Chem. Sci., 2012, 3, 2495-2500.

195 C. Mottillo, Y. Lu, M.-H. Pham, M. J. Cliffe, T.-O. Do and T. Friščić, Green Chem., 2013, 15, 2121.

196 F. Qi, R. S. Stein and T. Friščić, Green Chem., 2014, 16, 121-132.

197 I. Huskić and T. Friščić, Philos. Trans. R. Soc., A, 2019, 377, 20180221.

198 D. Crawford, J. Casaban, R. Haydon, N. Giri, T. McNally and S. L. James, Chem. Sci., 2015, 6, 1645-1649.

199 K. Užarević, T. C. Wang, S. Y. Moon, A. M. Fidelli, J. T. Hupp, O. K. Farha and T. Friščić, Chem. Commun., 2016, 52, 2133-2136.

200 B. Karadeniz, A. J. Howarth, T. Stolar, T. Islamoglu, I. Dejanović, M. Tireli, M. C. Wasson, S. Y. Moon, O. K. Farha, T. Friščić and K. Užarević, ACS Sustainable Chem. Eng., 2018, 6, 15841-15849.

201 W. Bury, I. Justyniak, D. Prochowicz, A. Rola-Noworyta and J. Lewiński, Inorg. Chem., 2012, 51, 7410-7414.

202 D. Prochowicz, K. Sokołowski, I. Justyniak, A. Kornowicz, D. Fairen-Jimenez, T. Friščić and J. Lewiński, Chem. Commun., 2015, 51, 4032-4035. 
203 J. C. Rybak and K. Müller-Buschbaum, Z. Anorg. Allg. Chem., 2010, 636, 126-131.

204 T. P. Vaid, S. P. Kelley and R. D. Rogers, IUCrJ, 2017, 4, 380-392.

205 G. A. V. Martins, P. J. Byrne, P. Allan, S. J. Teat, A. M. Z. Slawin, Y. Li and R. E. Morris, Dalton Trans., 2010, 39, 1758-1762.

206 S. Chen, J. Zhang, T. Wu, P. Feng and X. Bu, Dalton Trans., 2010, 39, 697-699.

207 L. Yang and H. Lu, Chin. J. Chem., 2012, 30, 1040-1044.

208 Z. Lian, L. Huimin and Y. Lisha, Mater. Lett., 2014, 125, 59-62.

209 K. Lu, A. Liebman Peláez, L. C. Wu, Y. Cao, C. H. Zhu and H. Fu, Inorg. Chem., 2019, 58, 1794-1805.

210 S. H. Zottnick, M. Finze and K. Müller-Buschbaum, Chem. Commun., 2017, 53, 5193-5195.

211 J. H. Cavka, S. Jakobsen, U. Olsbye, N. Guillou, C. Lamberti, S. Bordiga and K. P. Lillerud, J. Am. Chem. Soc., 2008, 130, 13850-13851.

212 X. Sang, J. Zhang, J. Xiang, J. Cui, L. Zheng, J. Zhang, Z. Wu, Z. Li, G. Mo, Y. Xu, J. Song, C. Liu, X. Tan, T. Luo, B. Zhang and B. Han, Nat. Commun., 2017, 8, 175.

213 P. Cintas and J.-L. Luche, Green Chem., 1999, 1, 115-125.

214 W. J. Son, J. Kim, J. Kim and W. S. Ahn, Chem. Commun., 2008, 6336-6338.

215 C. G. Carson, A. J. Brown, D. S. Sholl and S. Nair, Cryst. Growth Des., 2011, 11, 4505-4510.

216 D. A. Yang, H. Y. Cho, J. Kim, S. T. Yang and W. S. Ahn, Energy Environ. Sci., 2012, 5, 6465-6473.

217 H. Y. Cho, J. Kim, S. N. Kim and W. S. Ahn, Microporous Mesoporous Mater., 2013, 169, 180-184.

218 U. Mueller, M. Schubert, F. Teich, H. Puetter, K. SchierleArndt and J. Pastré, J. Mater. Chem., 2006, 16, 626-636.

219 R. Ameloot, L. Stappers, J. Fransaer, L. Alaerts, B. F. Sels and D. E. De Vos, Chem. Mater., 2009, 21, 25802582.

220 H. M. Yang, X. L. Song, T. L. Yang, Z. H. Liang, C. M. Fan and X. G. Hao, RSC Adv. , 2014, 4, 15720-15726.

221 A. Martinez Joaristi, J. Juan-Alcañiz, P. Serra-Crespo, F. Kapteijn and J. Gascon, Cryst. Growth Des., 2012, 12, 3489-3498.
222 A. J. Howarth, Y. Liu, P. Li, Z. Li, T. C. Wang, J. T. Hupp and O. K. Farha, Nat. Rev. Mater., 2016, 1, 15018.

223 M. Bosch, M. Zhang and H.-C. Zhou, Adv. Chem., 2014, 2014, 182327.

224 I. J. Kang, N. A. Khan, E. Haque and S. H. Jhung, Chem. Eur. J., 2011, 17, 6437-6442.

225 N. Li, J. Xu, R. Feng, T. L. Hu and X. H. Bu, Chem. Commun., 2016, 52, 8501-8513.

226 N. U. Qadir, S. A. M. Said and H. M. Bahaidarah, Microporous Mesoporous Mater., 2015, 201, 61-90.

227 M. E. A. Safy, M. Amin, R. R. Haikal, B. Elshazly, J. Wang, Y. Wang, C. Wöll and M. H. Alkordi, Chem. Eur. J., 2020, 26, DOI: $10.1002 /$ chem.202000207.

228 B. S. Gelfand and G. K. H. Shimizu, Dalton Trans., 2016, 45, 3668-3678.

229 J. Liang, Z. Liang, R. Zou and Y. Zhao, Adv. Mater., 2017, 29, 1-21.

230 V. Colombo, S. Galli, H. J. Choi, G. D. Han, A. Maspero, G. Palmisano, N. Masciocchi and J. R. Long, Chem. Sci., 2011, 2, 1311-1319.

231 E. V. Ramos-Fernandez, M. Garcia-Domingos, J. JuanAlcañiz, J. Gascon and F. Kapteijn, Appl. Catal., A, 2011, 391, 261-267.

232 M. Rose, B. Böhringer, M. Jolly, R. Fischer and S. Kaskel, Adv. Eng. Mater., 2011, 13, 356-360.

233 M. K. Smith and K. A. Mirica, J. Am. Chem. Soc., 2017, 139, 16759-16767.

234 F. Maya, C. Palomino Cabello, A. Figuerola, G. Turnes Palomino and V. Cerdà, Chromatographia, 2019, 82, 361375.

235 M. Kalaj, K. C. Bentz, S. Ayala, J. M. Palomba, K. S. Barcus, Y. Katayama and S. M. Cohen, Chem. Rev., 2020, DOI: 10.1021/acs.chemrev.9b00575.

236 M. L. Kim, E. H. Otal and J. P. Hinestroza, Cellulose, 2019, 26, 123-137.

237 H. N. Wang, X. Meng, L. Z. Dong, Y. Chen, S. L. Li and Y. Q. Lan, J. Mater. Chem. A, 2019, 7, 24059-24091.

238 A. Dhakshinamoorthy, M. Alvaro and H. Garcia, Chem. Commun., 2012, 48, 11275-11288.

239 P. Silva, S. M. F. Vilela, J. P. C. Tomé and F. A. Almeida Paz, Chem. Soc. Rev., 2015, 44, 6774-6803. 